Review

\title{
Advances in the Chemical Analysis and Biological Activities of Chuanxiong
}

\author{
Weixia Li, Yuping Tang *, Yanyan Chen and Jin-Ao Duan \\ Jiangsu Key Laboratory for High Technology Research of TCM Formulae, \\ Nanjing University of Chinese Medicine, Nanjing 210046, Jiangsu, China \\ * Author to whom correspondence should be addressed; E-Mail: yupingtang@njutcm.edu.cn; \\ Tel./Fax: +86-025-8581-1916.
}

Received: 28 June 2012; in revised form: 19 August 2012 / Accepted: 20 August 2012 /

Published: 6 September 2012

\begin{abstract}
Chuanxiong Rhizoma (Chuan-Xiong, CX), the dried rhizome of Ligusticum chuanxiong Hort. (Umbelliferae), is one of the most popular plant medicines in the World. Modern research indicates that organic acids, phthalides, alkaloids, polysaccharides, ceramides and cerebrosides are main components responsible for the bioactivities and properties of CX. Because of its complex constituents, multidisciplinary techniques are needed to validate the analytical methods that support CX's use worldwide. In the past two decades, rapid development of technology has advanced many aspects of CX research. The aim of this review is to illustrate the recent advances in the chemical analysis and biological activities of CX, and to highlight new applications and challenges. Emphasis is placed on recent trends and emerging techniques.
\end{abstract}

Keywords: Chuanxiong; organic acids; phthalides; alkaloids; polysaccharides; ceramides; cerebrosides

\section{Introduction}

Chuanxiong Rhizoma (named as Rhizoma Chuanxiong before 2010 in the Chinese Pharmacopoeia), the dried rhizome of Ligusticum chuanxiong Hort., known as Chuan-Xiong (CX) in folk medicine, and belonging to the Umbelliferae family, is one of the oldest and most popular herbal medicines in the World [1,2]. It has been used for thousands of years in traditional Chinese, Japanese, and Korean folk medicine [3]. It was firstly cited as "Xiong-Qiong" in Shennong's Classic of Materia Medica 
(200-300 A.D., Han Dynasty) an oldest Chinese herbal classical masterpiece [1,4]. Later, it was cited by the name "Chuan-Xiong", which has been used until today, in Yixue Qiyuan (Jin Dynasty, Zhang Yuansu) [5,6]. This herb is otherwise known as Senkyu (Jananese), Ch'onkung (Korean), and Szechuan lovage root (English), respectively. Senkyu, the dried rhizome of Cnidium officinale Makino (syn. L. officinale Kitagawa, Umbelliferae) which is the original plant of the important crude drug CX in China, is one of the most frequently occurring drugs in the prescriptions of traditional Chinese medicines (TCMs) used in Japan [7-10]. According to study, C. officinale and L. chuanxiong are closely related species with $98 \%$ sequence identity [11]. Some studies have shown that both of them had antioxidative activities, through their high free radical scavenging ability, they may exert vascular relaxant effect, and inhibitory effects on DNA damage and apoptosis induced by ultraviolet B in mammalian cells [12-14]. However, it is L. chuanxiong that is recorded by the Chinese Pharmacopoeia and applied commonly in China.

$\mathrm{CX}$ is an annual herb, and its growing period can be divided into six stages (Table 1). From ancient times until today, Chuanxiong Rhizoma has been harvested each year in late May. Furthermore, studies [15-17] also showed that the optimal harvest time for this herb is in the period from the middle of April to the end of May. The resources of CX are very rich and widespread, with the main production areas being Dujiangyan (original name: Guan County), Pengzhou, Xindu, and Chongzhou, Sichuan province, China. CX cultivated in Dujiangyan is traditionally recognized as the authentic and superior herb [18-20].

Table 1. The growth and development stages of CX.

\begin{tabular}{|c|c|c|c|c|c|c|c|c|c|}
\hline Stage & Aug. Sept. & Oct. & Nov. & Dec. & Jan. & Feb. & March & April & May \\
\hline \multicolumn{10}{|l|}{ Seeding } \\
\hline \multicolumn{10}{|c|}{ Stem emergence and growth } \\
\hline \multicolumn{10}{|c|}{ Senescene } \\
\hline \multicolumn{10}{|c|}{ Emergence of the secondary stems } \\
\hline \multicolumn{10}{|c|}{ Tillering } \\
\hline Rhizome expansion & & & & & & & & & \\
\hline
\end{tabular}

$\mathrm{CX}$ is warm in property and pungent in flavor, with the functions of activating qi, promoting blood circulation, expelling wind and alleviating pain, which has high medicinal value [21]. It is one of the major clinically used cardiovascular protective TCMs and a popular medicine widely used in prescriptions for the treatment of atherosclerosis [22], vasodilatation [23], thrombus formation [24], ischemic stroke [25,26], angina pectoris [27], and hypertension [28,29], because of its reputation for thousands of years in China of facilitating blood circulation and dispersing blood stasis [30,31]. Additionally, it also has antioxidant [7,14], neuroprotective [32,33], antiinflammatory [34], antibacterial [35], antiproliferative [36], and proapoptotic activities [37]. What is more, its medicinal value has been demonstrated by numerous experiments, pre-clinical studies and clinical trials $[33,35]$. Furthermore, it is widely applied in food preparation as a health protection, usually added to a soup, such as CX mutton soup and CX fish head soup [38]. It is not only used for medicinal purpose, but also for health care products, facial cosmetics, as a forage additive, tobacco flavor additive, natural preservative, and so on [39]. 
These bioactivities are attributed to the chemical constituents of CX. So far, more than 200 compounds have been isolated from this herb, more than 80 compounds of which belong to various different structural types that have been identified. These compounds can be grouped into five basic types believed to be responsible for the bioactivities of CX, namely phenols and organic acids, phthalides, alkaloids, polysaccharides, ceramides and cerebrosides. Except for these five major types, $\mathrm{CX}$ also includes mineral elements, and other types of compounds. The contents of these constituents may vary significantly due to geographic sources, harvesting and processing, and thus affect the therapeutic effects of CX. Therefore, comprehensive quality control is critical to ensure the efficacy and safety in clinical use. Due to the complicated chemical composition, sensitive, accurate and high-resolution analytical methods should be established for the simultaneous qualitative and quantitative analysis of constituents from CX. What is more, chemical analysis of TCMs is an important subject in biochemical, pharmaceutical and clinical researches.

In the past two decades, rapid development of technology has advanced many aspects of $\mathrm{CX}$ research. Therefore, in this review, we summarize the progress in chemical analysis and pharmacology of the major five types of natural products from $\mathrm{CX}$, and mainly focusing on the chemical structures, isolation, qualification, quantification, and biological activities. Due to the importance of fingerprint analysis [40,41], and the rich and wide spread of CX, the development of the chromatographic fingerprint of this herb is also discussed.

\section{Chemical Compounds and Bioactivities}

\subsection{Phenols and Organic Acids}

\subsubsection{Chemical Structures}

Phenols and organic acids are one kind of the major characteristic constituents in CX. So far, at least 18 phenols and organic acids have been obtained from this herb. The main chemical structures of these phenols and organic acids (compounds 1-18) are given in Figure 1 [42-49].

\subsubsection{Sample Preparation for Chemical Analysis}

CX contains different types of compounds, among which there are hydrophilic or hydrophobic, polar or nonpolar ones. Therefore, good sample preparation methods are necessary to ensure that most compounds are efficiently extracted. Several methods have been reported for the separation of some organic acids from CX, including thin layer chromatography (TLC) [50], reversed-phase high performance liquid chromatography (RP-HPLC) [51,52], HPLC-mass spectrometry (HPLC-MS) [53], capillary zone electrophoresis (CZE) [54], and immobilized liposome chromatography for compound 1 [55], HPLC-MS for compound 13 [56], gas chromatography-MS (GC-MS) for compounds 1 and 6 [57], and capillary electrophoresis (CE) for compounds $\mathbf{1}, \mathbf{2}$ and $\mathbf{1 2}$ [58]. Zhao et al. [59] developed a RP-HPLC method for the determination of five kinds of phenolic acids in CX: 1, 2, 3, 8, and 12. And on the basis of this method, compounds $\mathbf{1}$ and $\mathbf{2}$ are found to be the main phenolic acids in CX. Up to now, most literatures about organic acids from CX focus on the analysis of compound 1. More important, compound $\mathbf{1}$ is found to exist in free form, and $\mathbf{2}$ in esterified or insoluble-bound form. The phenolic 
acid, particularly compound $\mathbf{8}$, is unstable under alkaline conditions in air, and it is necessary to hydrolyze the sample under argon or nitrogen [60]. However, publications about other acids in CX are very few. Otherwise, several analysis methods for phenolic acids have been set up for a variety of other samples, such as Danggui [61], fruit [60], rice [62] and wine [63]. These works successfully demonstrate that, by optimizing the parameters for the eluent or carrier system, the high-resolution separation of a complicated acid mixture can be easily achieved.

Figure 1. Chemical structures of the identified phenols and organic acids in CX: (1) ferulic acid; (2) caffeic acid; (3) protocatechuic acid; (4) p-hydroxybenzoic acid; (5) vanillic acid; (6) vanillin; (7) sedanonic acid; (8) gallic acid; (9) chrysophanol; (10) 3-methoxy-4-hydroxystyrene; (11) 1-hydroxy-1-(3-methoxy-4-hydroxyphenyl)-ethane; (12) chlorogenic acid; (13) coniferyl ferulate; (14) 5-hydroxymethyl-6-endo-3-methoxy-4hydroxyphenyl-8-oxa-bicyclo(3.2.1)-oct-3-one; (15) folic acid; (16) palmitinic acid; (17) linoleic acid; (18) sinapic acid.

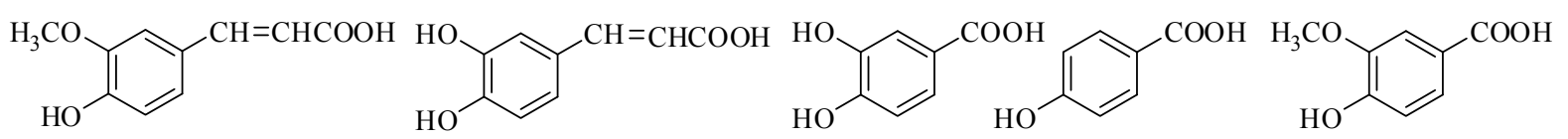

(1) (2)

(3)

(4)

(5)<smiles>C=Cc1ccc(O)c(OC)c1</smiles>

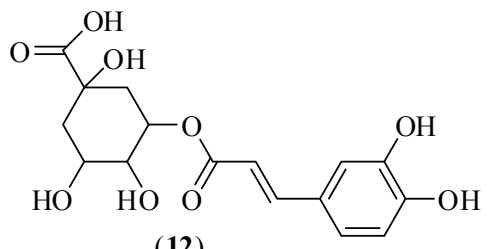

(12)

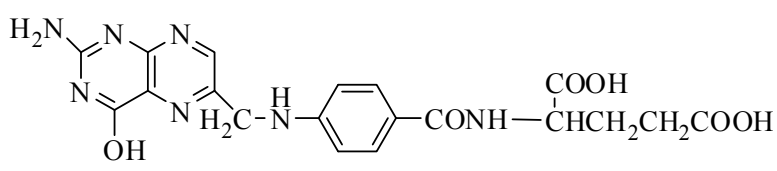

(15)<smiles>COc1cc(/C=C/COC(=O)/C=C/c2ccc(O)c(OC)c2)ccc1O</smiles>

(13)

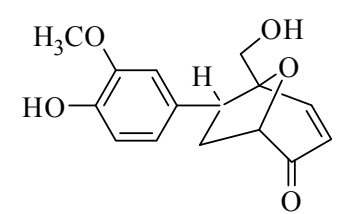

(14)<smiles>CCCCCC(C)(C)CC(=O)O</smiles>

\subsubsection{Quantitative Analysis}

Compound 1, one of the main effective components in CX, is widely used as one of the marker compounds to assess the quality of $\mathrm{CX}$ and its products [64,65]. In the reported literatures, the concentration of 1 in $\mathrm{CX}$ varies within the range of $0.107-2.374 \mathrm{mg} / \mathrm{g}$, quantified by a variety of methods (shown in Table 2) [42,51,66-76]. Additionally, it was also determined by other methods such as near-infrared spectroscopy (NIRS) [77]. Apart from the variation in natural abundance among the herb samples, the nature of extraction solvents and methods are likely to be a critical cause. CX sample is commonly extracted using a variety of solvents, namely: ethanol, methanol, methanol-water$36 \%$ acetic acid (30:67:3), methanol-36\% acetic acid (95:5), methanol-formic acid (95:5) and water under reflux, sonication, Soxhlet extraction and ultrasonic agitation, immersion extraction, decoction, followed by TLC, CE, and HPLC analysis. 
Table 2. The concentration variation of ferulic acid (1) in CX analyzed by different methods.

\begin{tabular}{|c|c|c|c|c|c|}
\hline No. & Extraction solvent & Extraction method & Analytical method & Content (mg/g) & Ref. \\
\hline 1 & $95 \%$ ethanol & Reflux & TLCS & 0.9395 & {$[67]$} \\
\hline 2 & $70 \%$ ethanol & Sonication & HPCE & $0.82 \sim 1.19$ & [66] \\
\hline 3 & Methanol & Sonication & $\begin{array}{l}\text { HPLC: PE-Pack C18 }(4.6 \mathrm{~mm} \times 150 \mathrm{~mm}, 5 \mu \mathrm{m}), 1 \% \text { glacial acetic } \\
\text { acid:methanol }(58: 42), 0.5 \mathrm{~mL} / \mathrm{min}, 313 \mathrm{~nm}\end{array}$ & $0.146 \sim 0.778$ & [68] \\
\hline 4 & $70 \%$ ethanol & Ultrasonic agitation & $\mathrm{CE}$ & $0.82 \sim 1.19$ & [42] \\
\hline 5 & $95 \%$ ethanol & Soxhlet extraction & $\begin{array}{l}\text { HPLC: Waters } \mathrm{C} 18(10 \mu \mathrm{m} \times 3.9 \mathrm{~mm} \times 250 \mathrm{~mm}), 10 \% \text { acetic } \\
\text { acid:methanol }(65: 35), 1 \mathrm{~mL} / \mathrm{min}, 320 \mathrm{~nm}\end{array}$ & $1.234 \sim 1.368$ & [69] \\
\hline 6 & $\begin{array}{l}\text { Methanol-water-36\% acetic acid } \\
(30: 67: 3)\end{array}$ & Sonication & $\begin{array}{l}\text { HPLC: ODS C18 }(250 \mathrm{~mm} \times 4.6 \mathrm{~mm}) \text {, methanol:water:36\% acetic } \\
\text { acid }(30: 67: 3), 1 \mathrm{~mL} / \mathrm{min}, 322 \mathrm{~nm}\end{array}$ & $0.653 \sim 1.327$ & {$[51]$} \\
\hline 7 & $\begin{array}{l}\text { Methanol-36\% acetic acid } \\
(95: 5)\end{array}$ & Sonication & $\begin{array}{l}\text { HPLC: Kromasil C18 }(250 \mathrm{~mm} \times 4.6 \mathrm{~mm}, 5 \mu \mathrm{m}) \\
\text { acetonitrile:methanol:1\% acetic acid }(15: 15: 70), 0.6 \mathrm{~mL} / \mathrm{min}\end{array}$ & $0.327 \sim 0.723$ & {$[70]$} \\
\hline 8 & SFE & - & $\begin{array}{l}\text { HPLC: Phenomenex }(250 \mathrm{~mm} \times 4.6 \mathrm{~mm}, 5 \mu \mathrm{m}) \\
\text { methanol:water:glacial acetic acid }(30: 70: 0.2), 1 \mathrm{~mL} / \mathrm{min}, 320 \mathrm{~nm}\end{array}$ & 0.8 & [71] \\
\hline 9 & Water & Reflux & $\begin{array}{l}\text { HPLC: DiamonsilTM C18 }(250 \mathrm{~mm} \times 4.6 \mathrm{~mm}, 5 \mu \mathrm{m}) \text {, } \\
\text { methanol:water:glacial acetic acid }(30: 68: 2), 1.0 \mathrm{~mL} / \mathrm{min}, 320 \mathrm{~nm}\end{array}$ & $1.87 \sim 2.17$ & {$[72]$} \\
\hline 10 & Methanol & Sonication & $\begin{array}{l}\text { RP-HPLC: Inertsil C18 }(250 \mathrm{~mm} \times 4.6 \mathrm{~mm}, 5 \mu \mathrm{m}) \text {, } \\
\text { methanol:water:glacial acetic acid }(35: 65: 0.5), 1.0 \mathrm{~mL} / \mathrm{min}, 321 \mathrm{~nm}\end{array}$ & $1.00 \sim 1.14$ & {$[73]$} \\
\hline 11 & $\begin{array}{l}\text { Methanol-formic acid } \\
(95: 5)\end{array}$ & Sonication & $\begin{array}{l}\text { HPLC: Kromasil C18 }(250 \mathrm{~mm} \times 4.6 \mathrm{~mm}, 5 \mu \mathrm{m}), 1 \% \text { acetic } \\
\text { acid:acetonitrile, } 1 \mathrm{~mL} / \mathrm{min}, 320 \mathrm{~nm}\end{array}$ & $0.107 \sim 2.374$ & {$[74]$} \\
\hline 12 & $40 \%$ ethanol & Water bath reflux & $\begin{array}{l}\text { HPLC: Lichrosorb C18 }(4.6 \mathrm{~mm} \times 250 \mathrm{~mm}, 5 \mu \mathrm{m}), 1 \% \text { acetic } \\
\text { acid:methanol }(70: 30), 1 \mathrm{~mL} / \mathrm{min}, 320 \mathrm{~nm}\end{array}$ & 1.141 & {$[75]$} \\
\hline 13 & $70 \%$ methanol & Reflux & $\begin{array}{l}\text { (1) HPLC: Agilent TC-C } 18(150 \mathrm{~mm} \times 4.6 \mathrm{~mm}, 5 \mu \mathrm{m}) \text {, } \\
\text { acetonitrile:0.085\% phosphoric acid }(17: 83), 1.0 \mathrm{~mL} / \mathrm{min}, 316 \mathrm{~nm} \\
\text { (2) UPLC: Acquity UPLC HSS T3 }(100 \mathrm{~mm} \times 2.1 \mathrm{~mm}, 1.8 \mu \mathrm{m}) \text {, } \\
\text { acetonitrile:0.085\% phosphoric acid }(15: 85), 0.3 \mathrm{~mL} / \mathrm{min}, 316 \mathrm{~nm}\end{array}$ & 1.21 & {$[76]$} \\
\hline
\end{tabular}




\subsubsection{Biological Activities}

Aromatic acids in the herbs are frequently used in TCM formula to stimulate blood circulation and to remove blood stasis by preventing platelet aggregation and antithrombus [78]. The pharmacological studies of organic acids mainly focus on the main constituents, including compounds $\mathbf{1}, \mathbf{2}$ and 12. Compound 1, a characteristic aromatic acid in CX, has been clinically used to treat angina pectoris and hypertensive diseases in China [79]. Previous investigations indicated that it could significantly improve blood fluidity, inhibit platelet aggregation, decrease serum lipids, prevent thrombus formation, protect neuron like pheochromocytoma cells (PC12), and exhibit strong antioxidant activity [28,80-84]. It was also reported that CX had anti-inflammatory action [85], could prevent ethanol-induced liver injury [86], contributed to the defense against viral infections including AIDS [87], as well as suppress the production of interleukin-8 (IL-8) which was the main cause of the local accumulation of neutrophils, and modulate various inflammatory reactions [85]. Compound 2 (3,4-dihydroxycinnamic acid) possesses anti-oxidant properties as it scavenges a number of reactive species, including 1,1-diphenyl-2-picrylhydrazyl (DPPH) free radical [88], peroxyl [89] and hydroxyl radicals [90], as well as superoxide anion, peroxynitrite and mutagenic compounds such as nitrosamines [91]. It also could inhibit 5-lipoxygenase activity [92], and inhibit protein kinase C, protein kinase (PKA) and nuclear factor $-\kappa B(\mathrm{NF}-\kappa \mathrm{B})$ activation induced by ceramides in U937 cells [93]. Compound 12 could inhibit carcinogenesis in the colon, liver, and tongue, and was against oxidative stress in vivo [94-96]. It has been claimed to modulate the glucose-6-phosphatase involved in glucose metabolism [97] and to reduce the risk of cardiovascular disease by decreasing oxidation of low density lipoprotein (LDL)-cholesterol and total cholesterol [98]. More recently, it has been reported that it can inhibit preadipocyte population growth, which may provide a proposed mechanism of reducing obesity [99].

\subsection{Phthalides}

\subsubsection{Chemical Structures}

Phthalides are one kind of active compounds in CX with a phthalide parent nucleus and are used as characteristic components for quality control. Chemical structures of the main phthalides in CX are shown in Figure 2a,b, containing monomeric phthalides (compounds 19-51) and phthalide dimers (compounds 52-66) [9,10,100-109]. Takashi et al. [100-103] isolated about 30 phthalides from this herb in the 1990s, several of which were reported for the first time. Nowadays, some new phthalide and dimeric phthalides are isolated from CX in succession, such as 4,7-dihydroxy-3-butylphthalide (43), ligusticoside A (63) (a novel phthalide derivative with a lactone ring), chuanxiongnolide A (64), chuanxiongnolide B (65), 4,5-dihydro-3,1'-dihydroxy-3-pentylphthalide, and 4-pentylcyclohex-3-ene1a,2b-diol [20,104,105]. Additionally, some compounds were found from this herb for the first time, such as $n$-hexadecanoic acid, daucosterol, 3-methylphthalide, and 3-butylidene-4,5-dihydro-2(1,3H)-1isobenzofuranone $[50,106]$. 
Figure 2. Chemical structures of main monomeric phthalides in CX: (19) Z-ligustilide; (20) E-ligustilide; (21) senkyunolide A; (22) senkyunolide B; (23) senkyunolide C; (24) senkyunolide D; (25) Z-senkyunolide E; (26) E-senkyunolide E; (27) senkyunolide F; (28) senkyunolide G; (29) senkyunolide H; (30) senkyunolide I; (31) senkyunolide J; (32) senkyunolide K; (33) senkyunolide L; (34) senkyunolide M; (35) senkyunolide N; (36) senkyunolide Q; (37) senkyunolide R; (38) senkyunolide S; (39) 3-butylphthalide; (40) 3-butylidenephthalide; (41) 3-butylidene-7-hydroxyphthalide; (42) 3-butyl-4hydroxyphthalide; (43) 4,7-dihydroxy-3-butylphthalide; (44) 4,5-dihydro-3-butylphthalide; (45) 4,5-dihydro-3-butylidenephthalide; (46) 3-butylidene-6-hydroxy-5,6-dihydrophthalide; (47) cnidilide; (48) neocnidilide; (49) 2-(1-oxopentyl)-benzoic acid methyl ester; (50) Z-6,7-epoxyligustilide; (51) 3-carboxyethyl-phthalide.<smiles>CCC/C=C1\OC(=O)C2=C1CCC=C2</smiles>

(19)<smiles>CCC(O)/C=C1\OC(=O)c2ccccc21</smiles>

(25)<smiles>CCC/C=C1/OC(=O)C2=C1CCC=C2</smiles>

(20)<smiles>CCC(O)C=C1OC(=O)c2ccccc21</smiles>

(26)<smiles>CCCC[C@H]1OC(=O)C2=C1CCC=C2</smiles>

(21)<smiles>CCC/C=C1\OC(=O)c2cccc(O)c21</smiles>

(22)<smiles>CC=C1OC(=O)c2ccc(O)cc21</smiles>

(23)<smiles>CCCC(=O)C1(O)OC(=O)c2ccccc21</smiles>

(24)<smiles>CCC/C=C1\OC(=O)C2=C1CC[C@@H](O)[C@H]2O</smiles>

(27)

(29)
(30)<smiles>CCCC=C1C(Cl)C(O)CCC2/C(=C/CCC)OC(=O)C12</smiles>
(31) (32)

(33)

(34)

(35)<smiles>CCC/C=C1\OC(=O)C2=C1CCC(CCCC)[C@@H]2O</smiles>

(36)<smiles>CCC/C=C1\OC(=O)c2c(O)cccc21</smiles>

(41)<smiles>CCCCC1OC(=O)C2=CC(O)CC=C21</smiles>

(46)<smiles>CCCCC1OC(=O)c2cccc(O)c21</smiles>

(42)<smiles>CCCCC1OC(=O)C2C=CCCC12</smiles>

(47)<smiles>CC[C@H](O)/C=C1\OC(=O)C2=C1CC[C@H](O)[C@H]2O</smiles>

(38)<smiles>CCCCC1OC(=O)c2ccccc21</smiles>

(39)<smiles>CCCCC1OC(=O)c2c(O)ccc(O)c21</smiles>

(43)<smiles>CCCCC1OC(=O)C2=C1CCC=C2</smiles>

(44)<smiles>CCC/C=C1\OC(=O)c2ccccc21</smiles>

(40)<smiles>CCC/C=C1\OC(=O)C2=C1CCC=C2</smiles>

(45)<smiles>CCCC(=O)c1ccccc1C(=O)OC</smiles>

(49)<smiles>C/C=C/CC/C=C1\OC(=O)C2C3CCC4OC4C3C12</smiles>

(50)<smiles>O=C(O)CC1OC(=O)c2ccccc21</smiles>

(51)

(a) 
Figure 2. Cont. Chemical structures of main phthalide dimers in CX: (52) senkyunolide O; (53) senkyunolide P; (54) levistolide A; (55) 3,8-dihydrodiligustilide; (56) tokinolide B; (57) ansaspirolide; (58) riligustilide; (59) (Z,Z')-6,8',7,3'-diligustilide; (60) angelicide; (61) $Z, Z^{\prime}-3,3$ ',8,8'-diligustilide; (62) Z-ligustilide dimer E-232; (63) ligusticoside A; (64) chuanxiongnolide A; (65) chuanxiongnolide B; (66) wallichilide.

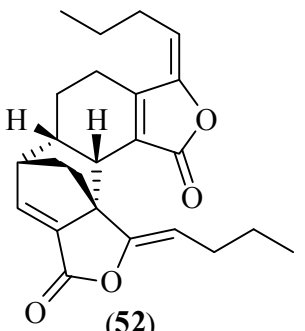

(52)

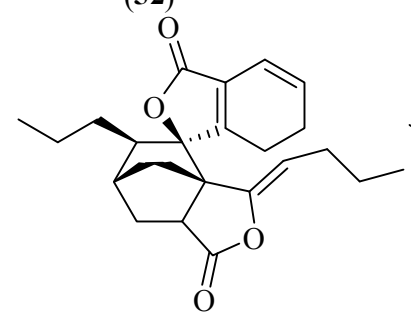

(56)<smiles>CCC/C=C1\OC(=O)C2C1CCC1C(CCC)C3CC12C31OC(=O)C2=C1CCC=C2</smiles>

(60)

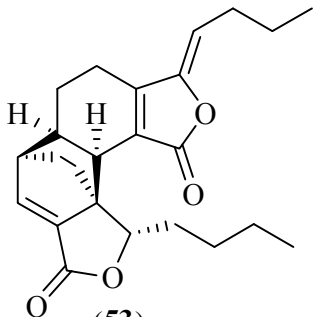

(53)

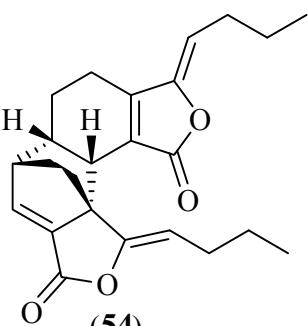

(54)<smiles>CCCC[C@H]1OC(=O)C2=C1CC[C@H]1CC[C@H]2C[C@@]12COC(=O)C2=O</smiles>

(55)

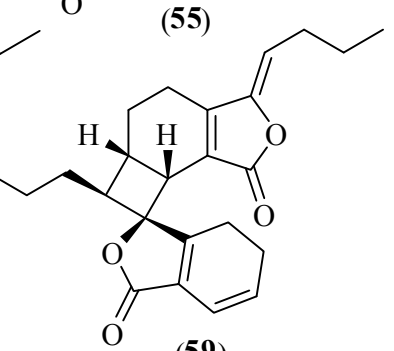

(58)

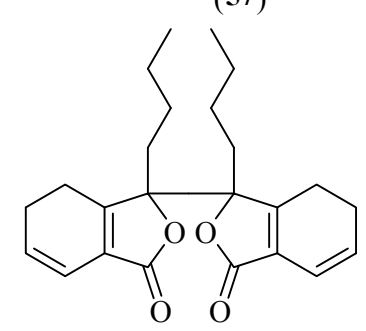

(61)

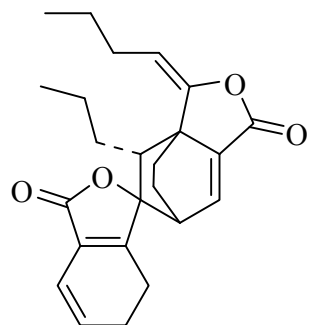

(62)
(63)

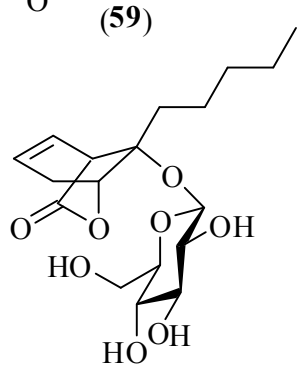

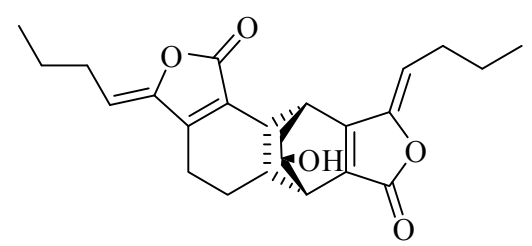

(64)

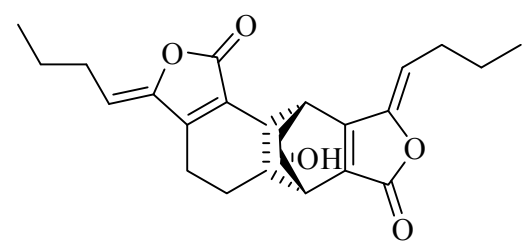

(65)

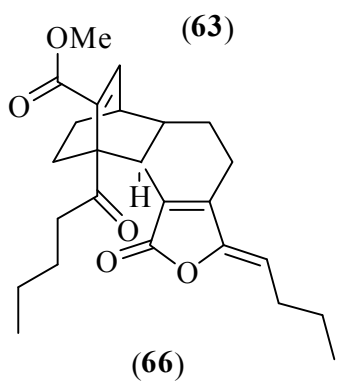

(b)

\subsubsection{Sample Preparation for Chemical Analysis}

In most literatures the phthalide compounds in CX are extracted as a part of the volatile oil by steam distillation, solvent extraction, supercritical fluid extraction, circulation extraction coupling with adsorption and other methods [110]. Solid phase extraction could effectively enrich the phthalide components in CX, and eliminate the interference of other components [111]. In order to improve the extraction process and develop a greener extraction, a microwave-assisted extraction (MAE) method was investigated. The components of different polarity could be enriched in ionic liquids by choosing different extraction solvents. The ionic liquid MAE method takes a short time with high extraction efficiency and with less solvent and energy consumption [112]. 
A RP-preparative-HPLC method for the isolation of compound $\mathbf{3 0}$ from CX was described by Zhang et al. [113]. Because it is difficult for traditional methods including semi-preparative HPLC and CE to avoid the adsorption on the solid phase, they are not very suitable for the separation of compounds 19 and/or 20 and their analogues. High speed counter current chromatography (HSCCC) is a kind of liquid-liquid chromatography separation technique which is developed in recent years, and provides an advantage over the conventional column chromatography by eliminating the use of a solid support where an amount of stationary phase is limited and dangers of irreversible adsorption from the support are inevitably present. And now, it is accepted as an efficient preparative technique, and widely used for separation and purification of various natural and synthetic products [114]. Compounds 19 and 21, the main components of volatile oil in CX, were separated in one step by HSCCC, and their purity could reach more than 95\%, indicating that phthalides were fit to be separated and prepared by HSCCC with good resolution and high purity [115].

\subsubsection{Quantitative Analysis}

Among the phthalides, compound $\mathbf{1 9}$ is frequently selected as a marker compound to evaluate the quality of CX. Concentration of ligustilide (19 and/or 20) in CX varies within the range of $5.672-15.700 \mathrm{mg} / \mathrm{g}$ in the reported literatures, which are quantified by a variety of methods (shown in Table 3) [116-121]. HPLC is the main analytical method for quantification of $\mathbf{1 9}$ and $\mathbf{2 0}$. Although the content of $19 \mathrm{and} /$ or $\mathbf{2 0}$ in CX was high, their instability and easy decomposition also brought about many problems for the determination. Compound 39 had a better stability than 19 and 20. Shan et al. $[122,123]$ determined the content of $\mathbf{3 9}$ in the volatile oil and crude herb of CX by HPLC (shown in Table 3). The results indicated the content of $\mathbf{3 9}$ in the volatile oil of CX was more than 17 times of that in CX crude herb.

HPLC with ultraviolet (UV) detection is increasingly used to analyze phthalides [124]. However, the sensitivity and selectivity of UV is insufficient for their direct identification in complex mixtures. GC-MS is a method that combines the features of gas-liquid chromatography and mass spectrometry, which was successfully used for simultaneous quantification of eight phthalides in essential oils from Si-Wu-Tang, Fo-Shou-San, Angelica Radix and CX [125]. However, the instability and structural similarity also cause difficulties in their analysis. Some of the volatile phthalides such as $\mathbf{1 9}$ are unstable and are easily changed into other phthalides through oxidation, isomerization, dimerization, or rapid decomposition at high temperature because of their active dihydrobenzene structure [126,127]. The dimeric phthalides, however, are also thermolabile; and retro-Diels-Alder reactions can easily take place even below $100{ }^{\circ} \mathrm{C}$, which can't be detected by GC-MS [128]. Therefore, application of HPLC coupled with MS is an attractive option to separate and identify such components [129-131].

\subsubsection{Biological Activities}

Phthalides exhibit an equally broad spectrum of bioactivity, including modulation of the central nervous system and cardiac function, protection against brain ischemia, smooth muscle relaxation, inhibition of smooth muscle cell proliferation, anti-platelet aggregation, anti-angina activity, antibacterial, antifungal, antiviral and phytotoxic activity [132-134]. 
Table 3. The concentration variation of ligustilide (19 and/or $\mathbf{2 0})$ and butylphthalide (39) in CX analyzed by HPLC.

\begin{tabular}{|c|c|c|c|c|c|c|c|c|c|c|}
\hline No. & Analytes & $\begin{array}{l}\text { Extraction } \\
\text { solvent }\end{array}$ & $\begin{array}{l}\text { Extraction } \\
\text { method }\end{array}$ & $\begin{array}{l}\text { Analytical } \\
\text { method }\end{array}$ & Stationary phase & Mobile phase & $\begin{array}{l}\text { Flow rate } \\
(\mathrm{mL} / \mathrm{min})\end{array}$ & $\begin{array}{l}\lambda_{\max } \\
(\mathbf{n m})\end{array}$ & $\begin{array}{l}\text { Content } \\
(\mathrm{mg} / \mathrm{g})\end{array}$ & Ref. \\
\hline 1 & ligustilide & - & - & HPLC & $\begin{array}{l}\text { Nova-Pak C18 } \\
(3.9 \mathrm{~mm} \times 150 \mathrm{~mm})\end{array}$ & $\begin{array}{l}\text { Methanol and water with } \\
10 \% \text { isopropanol }(53: 47)\end{array}$ & 0.8 & 280 & 15.7 & [116] \\
\hline 2 & ligustilide & Methanol & Sonication & HPLC & $\begin{array}{l}\text { Luna } 5 \mu \mathrm{m} \text { silica } \\
(150 \mathrm{~mm} \times 4.6 \mathrm{~mm})\end{array}$ & $\begin{array}{l}n \text {-hexane:ethyl acetate: } \\
\text { chloroform }(92: 3: 5)\end{array}$ & 0.8 & 320 & $15.27 \pm 1.86$ & [117] \\
\hline 3 & ligustilide & Acetonitrile & Shaking up & RP-HPLC & $\begin{array}{l}\text { Hypersil ODS2 } \\
(4.6 \mathrm{~mm} \times 200 \mathrm{~mm} \text {, } \\
5 \mu \mathrm{m})\end{array}$ & $\begin{array}{l}\text { Methanol:acetonitrile:water } \\
(33: 21: 46)\end{array}$ & 0.8 & 275 & $\begin{array}{l}347.9 \\
\text { (in volatile oil) }\end{array}$ & [118] \\
\hline 4 & ligustilide & Ethanol & Reflux & HPLC & $\begin{array}{l}\mathrm{C} 18 \\
(4.0 \mathrm{~mm} \times 200 \mathrm{~mm}, \\
5 \mu \mathrm{m})\end{array}$ & $\begin{array}{l}\text { Acetonitrile:water (both } \\
\text { contain } 0.1 \% \text { acetic acid) }\end{array}$ & 0.76 & 280 & 8.2 & [119] \\
\hline 5 & ligustilide & $\begin{array}{l}70 \% \\
\text { ethanol }\end{array}$ & Reflux & HPLC & $\begin{array}{l}\text { ODS C18 } \\
(4.6 \mathrm{~mm} \times 200 \mathrm{~mm}, \\
5 \mu \mathrm{m})\end{array}$ & $\begin{array}{l}\text { Methanol:water:acetic acid } \\
(75.0: 24.8: 0.2)\end{array}$ & 1.0 & 326 & $5.672 \sim 5.821$ & [120] \\
\hline 6 & ligustilide & Ethanol & Sonication & HPLC & $\begin{array}{l}\text { Alltima C18 } \\
(4.6 \mathrm{~mm} \times 150 \mathrm{~mm} \text {, } \\
5 \mu \mathrm{m})\end{array}$ & $\begin{array}{l}\text { Acetonitrile:water } \\
(60: 40)\end{array}$ & 1.0 & 350 & 7.40 & [121] \\
\hline 7 & butylphthalide & Acetonitrile & Shaking up & RP-HPLC & $\begin{array}{l}\text { Kromasil C18 } \\
(250 \mathrm{~mm} \times 4.6 \mathrm{~mm}, \\
5 \mu \mathrm{m})\end{array}$ & $\begin{array}{l}\text { sodium acetate } \\
(0.05 \mathrm{~mol} / \mathrm{L}): \text { acetonitrile } \\
(45: 55)\end{array}$ & 1.0 & 228 & $\begin{array}{l}131.2 \sim 138.3 \\
\text { (in volatile oil) }\end{array}$ & {$[122]$} \\
\hline 8 & butylphthalide & Ethyl ether & Sonication & RP-HPLC & $\begin{array}{l}\text { Kromasil C18 } \\
(250 \mathrm{~mm} \times 4.6 \mathrm{~mm}, \\
5 \mu \mathrm{m})\end{array}$ & 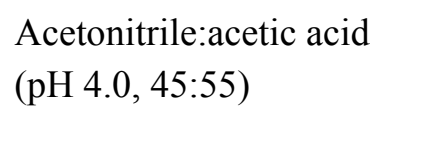 & 1.0 & 228 & $7.86 \sim 8.01$ & [123] \\
\hline
\end{tabular}


Among the phthalides, the main bioactive constituent focuses on compound 19, which has been studied and demonstrated that it has properties of vasodilatation [135], antiasthmatic action [136,137], antiplatelet aggregation [138], analgesic [139], antithrombotic, antiproliferation [140], centrally acting on muscle relaxant [141], on central noradrenergic and/or $\gamma$-aminobutyric acid [GABA(A)] systems [142] In addition, recent studies showed that it exerted significant neuroprotective effects in transient forebrain ischemia, permanent cerebral focal ischemia, and chronic cerebral hypoperfusion [143-145]. Both constituents of 19 and $\mathbf{2 1}$ were reported to have an anti-inflammatory effect by inhibiting tumor necrosis factor-alpha (TNF- $\alpha$ ) production and TNF- $\alpha$-induced NF- $\kappa \mathrm{B}$ activation in vitro $[34,146]$, vasorelaxation activities in contractions to various contractile agents in rat isolated aorta [147]. Both compounds 19 and 40 can inhibit the abnormal proliferation of vascular smooth muscle cell (VSMC) induced by basic fibroblast growth factor (bFGF) [148], attenuate the suppressive effects of yohimbine (30 nmol, i.c.v.), methoxamine (200 nmol, i.c.v.) and a benzodiazepine inverse agonist FG7142 $(10 \mathrm{mg} / \mathrm{kg}$, i.p.) on pentobarbital sleep in group-housed mice [138].

\subsection{Alkaloids}

\subsubsection{Chemical Structures}

Chemical structures of the main alkaloids from CX are shown in Figure $3[45,63,149]$. Tetramethylpyrazine (TMP, 67), the molecular formula $\mathrm{C}_{8} \mathrm{H}_{12} \mathrm{~N}_{2}$, is a characteristic alkaloid isolated from CX. Because compound $\mathbf{6 7}$ had the same pharmacological roles as CX and was first isolated from this herb, it was named chuanxiongzine by researchers.

Figure 3. Chemical structures of main alkaloids in CX: (67) tetramethylpyrazine; (68) L-isobutyl-L-valine anhydride; (69) L-valine-L-valine anhydride; (70) uracil; (71) adenine; (72) trimethylamine; (73) choline; (74) 1-acetyl- $\beta$-carboline; (75) 1- $\beta$-ethyl acrylate-7-aldehydo- $\beta$-carboline; (76) pelolyrine; (77) adenosine.<smiles>Cc1nc(C)c(C)nc1C</smiles>

(67)<smiles>C[N+](C)(C)CCO</smiles>

(73)<smiles>CCC(C)C1NC(=O)C(C(C)C)NC1=O</smiles>

(68)

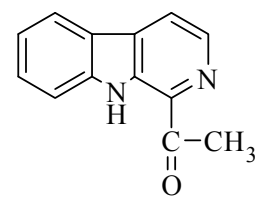

(74)<smiles>CC(C)C1NC(=O)C(C(C)C)NC1=O</smiles>

(69)<smiles></smiles>

(70)<smiles>CN(C)C</smiles>

(71)

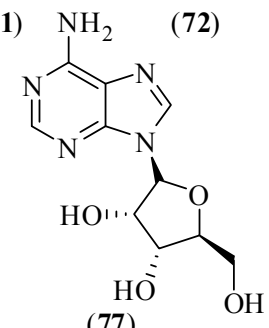

\subsubsection{Sample Preparation for Chemical Analysis}

Compound 67 in CX was extracted by SFE with a new class of low-pressure solvent (Phytosol), which is a non-chlorinated halothane solvent. During the extraction, just $30 \mathrm{~mL}$ of Phytosol solvent were needed, which could be recovered at room temperature [150]. CX total extract with high quality and stable yield could be obtained by another method of ethanol reflux and separation with 
macroporous resin. The extract yield was $0.6 \%$, among which compound 67 accounted for 5\% 7\% [151]. Ultrasonic extraction was also used in the extraction of 67, which is a new technology in extraction and separation of the active components in the herbal medicine in recent years. Compared with the conventional method of decoction, distillation and solvent immersion, the ultrasonic method had the advantages of a low extraction temperature, high biological activity of the product, less solvent consumption, time and energy savings [152]; extraction time of ultrafine vibration extraction technology (UVET) was $1 / 6$, solvent amount was $4 / 7$, the extraction rates of marker components (1 and 67) were 1.09 and 1.19 times, respectively [153].

\subsubsection{Quantitative Analysis}

Compound 67 has also been considered as one of the main bioactive components and is used as a chemical marker for quality control of $\mathrm{CX}$ herb and $\mathrm{CX}$-containing preparations (shown in Table 4) [8,154-156]. However, literature results suggest that the content of $\mathbf{6 7}$ was very low in CX, which was often less than the lower detection limit by HPLC [8]. Therefore, it should not be considered a suitable chemical marker for the quality control of CX herb and CX-derived herbal products.

Table 4. The concentration variation of TMP (67) in CX analyzed by different methods.

\begin{tabular}{|c|c|c|c|c|}
\hline Extraction solvent & Extraction method & Analytical method & Content (mg/g) & Ref. \\
\hline $\begin{array}{l}\text { Benzene, ethyl ether, and } \\
\text { ethyl acetate }\end{array}$ & Refluxing & HPLC-DAD & $1.2 \times 10^{-4}$ & {$[8]$} \\
\hline Petroleum ether & Counter current & RP-HPLC & $0.12 \times 10^{-3} \sim 0.87 \times 10^{-3}$ & [154] \\
\hline Ethanol & Sonication & HSCCC & 0.042 & [155] \\
\hline $\begin{array}{l}80 \% \text { ethanol (containing } \\
5 \% \text { acetic acid) }\end{array}$ & Sonication & HPLC & $0.01256 \sim 0.07252$ & [156] \\
\hline
\end{tabular}

Total quaternary ammonium alkaloids in CX were determined by neutralization titration, acidic dye colorimetry, and Reinecke salt colorimetry. The results from acidic dye colorimetry showed that among three kinds of CX species (Nai-CX, Shan-CX, and CX), the content of total alkaloids in CX was the highest [157]. Acidic dye colorimetry, however, had weak sensitivity and complex sample processing, which could easily cause error. Therefore, the content of total alkaloids in CX was determined by Reinecke salt colorimetry. Determined by this method, the content of total alkaloids in CX was $0.265 \%$. However, it was $0.237 \%$ determined by acidic dye colorimetry [158]. In order to inherit and develop our traditional "Paozhi" technology and better serve for clinic, the content of alkaloid in $\mathrm{CX}$ and $\mathrm{CX}$-processed products ( $\mathrm{Cu}-\mathrm{CX}$ and Jiu-CX) were determined by neutralization titration and TLC scanning method [159]. The content of compound 67 in Jiu-CX was lower than that in CX raw herb, but the content of total alkaloids was higher. It was probably because the melting point of 67 was $80 \sim 82^{\circ} \mathrm{C}$, so it was easily sublimed when it was heated. The contents of total alkaloids and compound 67 in $\mathrm{Cu}-\mathrm{CX}$ both were higher than that in $\mathrm{CX}$ raw herb, which might be attributed to the salt formation from alkaloid and acid which could be easily extracted. 


\subsubsection{Biological Activities}

Compound 67, an active compound of $\mathrm{CX}$, has been reported to be an agent against platelet aggregation [160], a vasodilator with calcium channel blocking activity [161], a scavenger of superoxide anion in human polymorphonuclear leukocytes [162], and a chemical with anti-portal hypertensive and hepatoprotective effects $[163,164]$. Recently, it was discovered to have protective effects on multiple organs and systems [165], to alleviate kidney and brain damage induced by ischemia/perfusion in rats via scavenging oxygen-free radicals [166], to postpone chronic renal allograft dysfunction associated with cold ischemia injury and chronic allograft rejection but to have no evident hepatic side effects [167]. Moreover, compound 67 could significantly suppress oxidative stress and attenuate cell death in neuronal cultures induced by glutamate analogue and iron-mediated oxidative stress [168,169]. It also shows anti-apoptotic effect in rabbit ischemic spinal cord and hydrogen peroxide $\left(\mathrm{H}_{2} \mathrm{O}_{2}\right)$-induced PC12 [170,171].

\subsection{Polysaccharides}

\subsubsection{Chemical Structures}

The components in CX have drawn the attention of researchers since around the 1950s. However, researchers have only started the study of polysaccharides in CX in 2004. Since then, studies have been gradually expanded. Four homogeneous polysaccharides were obtained from the water extract of CX for the first time, with the molecular weights of $3.1 \times 10^{4}, 5.2 \times 10^{4}, 9.0 \times 10^{4}$, and $3.6 \times 10^{4}$, respectively $[172,173]$. Polycose in CX is composed by arabinose (Ara), galactose (Gal) and glucose (Glc), in a molar ratio of 1:1.4:7.9, determined by filter paper chromatography, TLC, and vapor phase chromatography [174]. Additionally, three purified polysaccharides (LCA, LCB, and LCC) were obtained [38]. The estimated weight is around $2.83 \times 10^{4} \mathrm{Da}, 1.23 \times 10^{4} \mathrm{Da}$, and $6.31 \times 10^{4} \mathrm{Da}$, respectively. LCA is $\alpha$-Glc linkaged pyranose, composed by Ara, Gal, and mannose (Man). LCB consists of Ara, Glc, Gal, and Man; while LCC comprises Ara, Glc, and Gal. The result of Sun et al. [175] were in agreement with other literatures, except for the LCP-3, which still included rhamnose, galacturonic acid except Glc, Gal, Ara and Man, as determined by HPLC method after derivatization.

\subsubsection{Sample Preparation for Chemical Analysis}

At present, there are many methods for the extraction of polysaccharides, including water diffusion, osmosis, reflux, basic, ultrasonic, microwave, enzyme, supercritical fluid extraction (SFE) and macroporous resin methods (shown in Table 5) [176-182]. As indicated, both the pectinase method and cellulose method had higher extraction rates of polysaccharide from CX. Additionally, the enzyme method had mild reaction conditions and relatively simple operation compared with other methods. 
Table 5. The extraction methods of polysaccharide in CX.

\begin{tabular}{llll}
\hline Extraction method & Optimum technology & Extraction rate (\%) & Ref. \\
\hline Ultrasonic & $\begin{array}{l}\text { Ultrasonic time: } 40 \text { min; ultrasonic power: } 400 \mathrm{~W} ; \\
\text { solid to liquid ratio: } 1: 10 \text {; extraction times: } 2\end{array}$ & 2.74 & {$[176]$} \\
Pectinase & $\begin{array}{l}\text { Compound pectinase: } 1 \% \text {; temperature: } 60{ }^{\circ} \mathrm{C} ; \\
\text { pH value: } 3.5 \text {; the heating time: } 150 \text { min }\end{array}$ & 11.3 & {$[177]$} \\
Basic & $\begin{array}{l}\text { Extraction temperature: } 95{ }^{\circ} \mathrm{C} \text {; Extraction time: } \\
150 \text { min; the concentration of } \mathrm{NaOH}: 0.8 \mathrm{~mol} / \mathrm{L} ;\end{array}$ & 2.69 & {$[178]$} \\
& $\begin{array}{l}\text { solid to liquid ratio: } 1: 200 \mathrm{~g} / \mathrm{mL} \\
\text { Cellulase: } 0.15 \% \text {; the compound pectinase: } 10 \% \text {; } \\
\text { time: } 210 \text { min; } \mathrm{pH}: 3.4 \text {; temperature: } 60{ }^{\circ} \mathrm{C}\end{array}$ & 3.03 & {$[179]$} \\
Microwave assisted & $\begin{array}{l}\text { Microwave power: } 231 \mathrm{~W} \text {; solid to liquid ratio: } \\
1: 40 ; \text { extraction time: } 10 \text { min }\end{array}$ & 3.06 & {$[180]$} \\
Cellulose enzymic & $\begin{array}{l}\text { Cellulase: } 0.25 \% \text {; time: } 120 \text { min; pH value: } 4.0 ; \\
\text { temperature: } 50{ }^{\circ} \mathrm{C} .\end{array}$ & 7.26 & {$[181]$} \\
Basic & Extraction temperature: $90{ }^{\circ} \mathrm{C}$; extraction time: $4 \mathrm{~h}$. & 6.7 & {$[182]$} \\
\hline
\end{tabular}

During the extraction of polysaccharide in CX, the color of the extract was very deep, which might interfere with the quantitative determination. Therefore, it is necessary to decolorize the extract using absorbite, $\mathrm{H}_{2} \mathrm{O}_{2}$ and macroporous adsorptive resins. The results showed that macroporous adsorptive resins S- 8 had the best decolorization effect. The rate of decolorization was $92.7 \%$, and the retention rate of polysaccharide of CX was 93.0\% [183].

\subsubsection{Quantitative Analysis}

Polysaccharides generally should be hydrolyzed before quantitative determination. Then, reducing sugars can be determined by the carbolic acid method, sulphuric acid method, anthrone method, salicylic acid colorimetric method, Fehling reagent method or phenol method. Through weight calculations, the yield of crude polycose was $6.7 \%$. The polycose was $4.11 \%$ as determined by the carbolic acid method, sulphuric acid method, and anthrone method [174]. However, manual operation, which can't accomplish rapid monitoring and on-line analysis, is slow and involves more consumption of reagent. Therefore, a simple and rapid method of flow injection on-line hydrolysis spectrophotometry for the determination of polysaccharide in CX was developed [184]. It has been applied to a rapid determination of polysaccharide in CX with satisfactory results. The content of polysaccharide in CX was $2.28 \%$.

\subsubsection{Biological Activities}

It was shown that all purified polysaccharides (LCA, LCB, and LCC) exhibited antioxidation and cytotoxicity. Among them, LCB has the highest antioxidant and cytotoxic activity, and scavenging ability on hydroxyl radicals. It is possible that LCB can be explored as a novel potential antioxidant and cytotoxic natural bioactive macromolecule [38]. Additionally, the polysaccharides of CX have antibacterial activities and promote cell growth [185]. 


\subsection{Ceramides and Cerebrosides}

\subsubsection{Chemical Structures}

Ceramides and cerebrosides, two families of sphingolipids, are important components of a wide variety of tissues and organs in biological systems (fungi, plants, animals, and marine organisms). Chemically, ceramide usually consists of a long-chain sphingosine or sphingol and an amide-linked long-chain fatty acid; cerebrosides are composed of a hexose and a ceramide moiety. Yang et al. [186] isolated three ceramides (compounds 78-80) and two cerebrosides (compounds 81, 82) from the petroleum ether extract of CX in 2009. Amongst them, compounds $\mathbf{7 8}$ and $\mathbf{7 9}$ were new ceramides, compound $\mathbf{8 0}$ was a known ceramide, $\mathbf{8 1}$ and $\mathbf{8 2}$ were two known ceramides, but 80-82 were isolated from CX for the first time. Their structures are shown in Figure 4.

Figure 4. Chemical structures of the main ceramides and cerebrosides in CX: (78) (2R)-2-hydroxy- $N$-[(2S,3S,4R,8E)-1,3,4-trihydroxypentadec-8-en-2-yl]heptacosanamide; (79) (2R)-2-hydroxy- $N$ - $\{(3 S, 4 S, 5 S)$-4-hydroxy-5-[(4E)-undec-4-en-1-yl]tetrahydrofuran-3yl \}heptacosanamide; (80) (2R)-2-hydroxy- $N$-[(2S,3S,4R,8E)-1,3,4-trihydroxyicos-8-en-2yl]tetracosanamide; (81) (2R)- $N$-[(2S,3R,4E,8E)-1-( $\beta$-D-glucopyranosyloxy)-3-hydroxydodeca-4,8-dien-2-yl]-2-hydroxydocosanamide; (82) $(2 R)-N$-[(2R,3S,4R,8E)-1-( $\beta$-D-glucopyranosyloxy)-3,4-dihydroxyoctadec-8-en-2-yl]-2-hydroxyhexadecanamide.

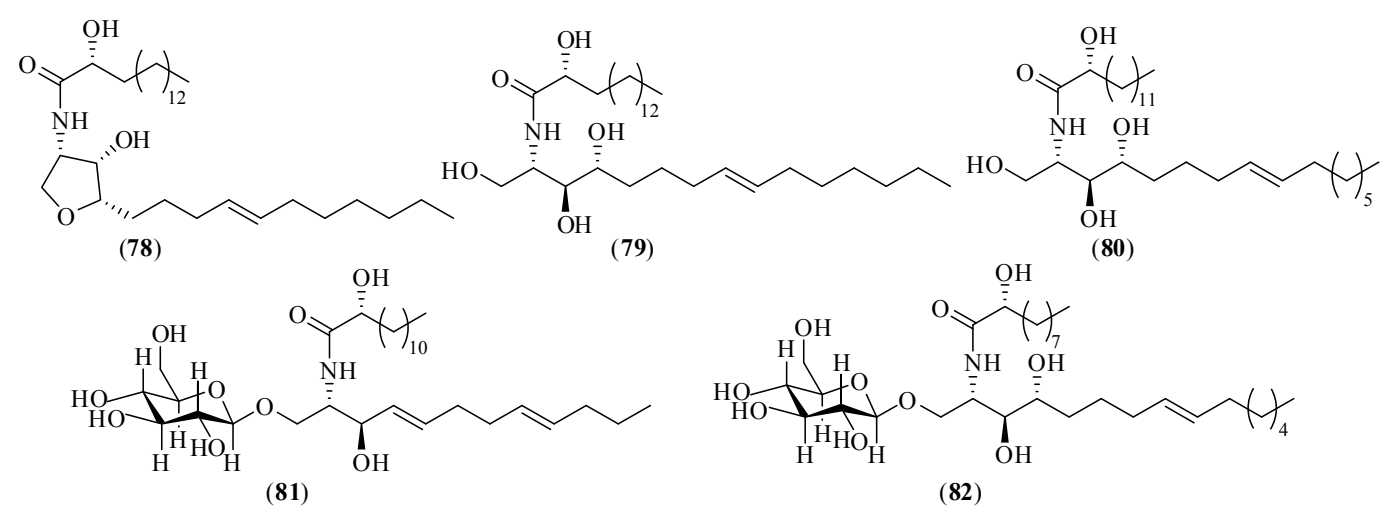

\subsubsection{Biological Activities}

The content of ceramides and cerebrosides in plants is very low. However, they have strong biological activities. A growing amount of evidence has indicated that ceramides and cerebrosides have a wide range of biological functions regulating cell growth and variation, participating in protein secretion and immunologic processes, protecting nerves, angiocarpy and liver cells. Biologically, cerebrosides have been proven to serve as structural supports and texture determinants of cell membranes, and to act as mediators of biological events [186-188].

\subsection{Other Compounds}

In addition to the above five types of components, $\mathrm{CX}$ also contains other compounds. Chemical components of CX aerial parts were studied using various separation methods, such as silica gel column chromatography, ODS column chromatography, and Sephadex LH-20. Twenty five 
compounds were separated and purified from a $80 \%$ ethanol extract of $\mathrm{CX}$ aerial parts. According to the physical and chemical properties, six compounds which were isolated from CX for the first time were identified using MS, ${ }^{1} \mathrm{H}-\mathrm{NMR},{ }^{13} \mathrm{C}-\mathrm{NMR}$, distortionless enhancement by polarization transfer (DEPT), heteronuclear single quantum coherence (HSQC) and heteronuclear multiple-bond correlation (HMBC). Scopoletin (83) and astragalin (84) were separated from the ethyl acetate fraction of the dried $80 \%$ ethanol extract of $\mathrm{CX}$ aerial parts; ergosterol peroxide $(\mathbf{8 5})$, daidzein (86), aurantiamide acetate (87) and lignoceric acid (88) were separated from the petroleum ether fraction [189]. Eleven compounds were separated and purified from $95 \%$ ethanol extract of CX by Hao et al. by repeated purification on a silica gel column, Sephadex LH-20 column chromatography, preparative TLC, and semi-preparative HPLC. Monopalmitin (89) and succinic acid (90) were separated from the petroleum ether and chloroform fractions of the dried 95\% ethanol extract of CX [190]. Furthermore, the dried methanol extract of the $80 \%$ ethanol crude extract was subjected to column chromatography on silica gel eluted with a gradient system of chloroform/methanol (100:0 to 80:20) to afford 12 fractions. (-)-Alloaromadendrane-4 $\beta, 10 \alpha, 13,15$-tetrol (91) was separated and purified from the fraction eluted from silica gel with chloroform/methanol (20:1), followed by reverse phase column chromatography eluted with methanol/ $\mathrm{H}_{2} \mathrm{O}$ (30:70). The fraction eluted with petroleum ether/ethyl acetate (15:1 to 12:1), was further subjected to column chromatography on silica gel to yield campest-4-en-3-one (92) [191]. Isolated compounds 91 and 92 were tested for their abilities to inhibit the growth of microorganisms, and the results showed that they all had mild antimicrobial activities. Their structures are shown in Figure 5.

Figure 5. Chemical structures of other compounds in CX: (83) scopoletin; (84) astragalin; (85) ergosterol peroxide; (86) daidzein; (87) aurantiamide acetate; (88) lignoceric acid; (89) monopalmitin; (90) succinic acid; (91) (-)-alloaromadendrane-4 $\beta, 10 \alpha, 13,15$-tetrol; (92) campest-4-en-3-one.

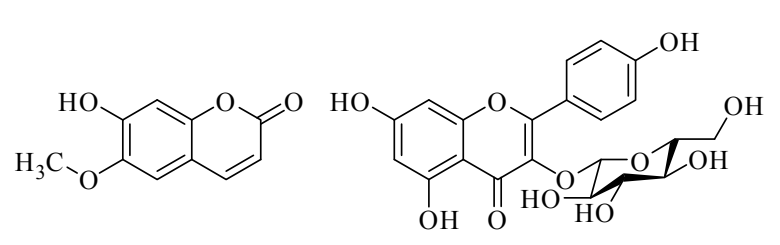

(83)<smiles>O=c1c(-c2ccc(O)cc2)coc2cc(O)ccc12</smiles>

(86)<smiles>O=C(NC(CCl)Cc1ccccc1)c1ccccc1</smiles>

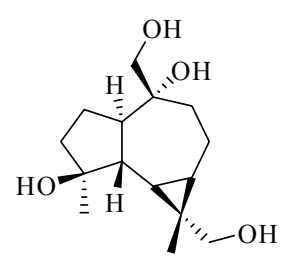

(91)

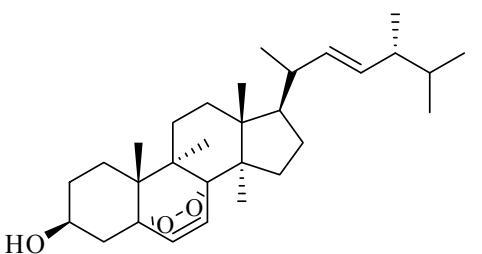

(85)<smiles>CCCCCCCCCCCCCCCCCCCCCCCCCCCCCCCCCCCCCC</smiles>

(88)<smiles>CCCCCCCCCCCCCCCC(=O)OCC(O)CO</smiles>

(89)<smiles>CC(C)C(C)CCC(C)C1CCC2C3CCC4=CC(=O)CC[C@]4(C)C3CC[C@]12C</smiles>

(92) 


\section{Analytical Methods for Simultaneous Determination of Different Types of Chemical Compounds}

\subsection{HPLC and HPLC-MS}

According to the development profile of CX (Table 1), fresh CX samples (October 8, 2002; October 30, 2002; December 2, 2002; January 2, 2003; February 11, 2003; March 9, 2003; April 11, 2003; April 17, 2003; April 24, 2003; May 2, 2003; May 9, 2003; May 15, 2003; and May 20, 2003) were collected and analyzed using HPLC-UV, and the results showed that all samples contained compounds 13, 19 and $\mathbf{2 1}$ as the major and compounds $\mathbf{1}$ and $\mathbf{4 0}$ as the minor components, while only trace amounts of components $\mathbf{5 4}$ and $\mathbf{5 8}$ were found in some of the samples. Compounds $\mathbf{2 9}$ and $\mathbf{3 0}$ were not detected in fresh CX herb, but detected in commercial dried and/or processed CX, which suggests they might be generated by the chemical conversion of the major phthalide 19 during processing and/or storage. Both individual and total contents of all main bioactive components gradually increased from the beginning of October to the middle of next April; and the weight of a single rhizome reached a plateau at the end of May, whilst the content of the major ingredients $(\mathbf{1 3}, 19$ and 21) peaked in the middle of April. Therefore, the optimal harvest time for this herb is in the period from the middle of April to the end of May when the node of the plant stem becomes swollen and purplish [16].

To date, HPLC has been extensively applied to the qualitative and quantitative analysis of chemical constituents of CX, including organic acids, phthalides, and alkaloids, and remains the prime method in compositional analysis of this herb. Representative HPLC methods developed for the simultaneous determination of chemical analysis of CX are summarized in Table 6 [8,59,110,119,192-201]. From it we can see that most HPLC separations of CX were carried out on reversed phase C18 columns, and some were on reversed phase C8 columns. In recent years, hyphenated HPLC techniques like HPLC-MS coupled with DAD, UV, and ESI focusing on structure elucidation have become widely available. With the aid of these modern spectroscopic techniques, multiple components of CX were simultaneously determined and identified. Phthalide dimers, present in smaller amounts, also have been identified by HPLC-UV and HPLC-MS. Stereochemical features of some phthalide monomers have been determined by detailed spectroscopic studies for the first time [202]. Additionally, some phthalides of CX are unstable and difficult to analyze by GC-MS. But they can unambiguously be identified by optimized LC-MS, and characteristic fragments of them can be obtained using homemade reference standards [203]. What is more, as a typical form of multi-dimensional separation system, a comprehensive two-dimensional LC system has been widely used to characterize and separate biomolecules, polymers, and other complex mixtures due to its high peak capacity, powerful separation and resolution ability since it appeared in 1978 [204]. The comprehensive two-dimensional system can provide maximum information with minimal amounts of material and allow rigorous quantitative interpretation of the results. Therefore, a comprehensive two-dimensional LC separation system based on the combination of a CN column and an ODS column was developed for the separation of components of CX [205]. Two columns are coupled by a two-position, eight-port valve equipped with two storage loops and controlled by a computer. More than 52 components in the methanol extract of CX were resolved and 11 (compounds $1,2,3,6,19,29,30,39,40,42$, and 44) of them were preliminary identified according to their UV and mass spectra. 
Table 6. HPLC methods developed for simultaneous chemical analysis of CX.

\begin{tabular}{|c|c|c|c|c|c|}
\hline No. & Analytes & Detection mode & Stationary phase & Mobile phase & Ref. \\
\hline 1 & $1,6,29,30$ and 67 & HPLC-MS & $\begin{array}{l}\text { Zorbax SB-C18 } \\
(250 \mathrm{~mm} \times 4.5 \mathrm{~mm}, 5 \mu \mathrm{m})\end{array}$ & $\begin{array}{l}\text { Methanol:water:acetic acid (45:55:0.5, } \\
\mathrm{v} / \mathrm{v} / \mathrm{v})\end{array}$ & [8] \\
\hline 2 & $1,6,13,19,21,27,29,30,31,39,40,47,48,53,54,56$ and 58 & HPLC-DAD-MS & $\begin{array}{l}\text { Waters symmetry C18 } \\
(150 \mathrm{~mm} \times 2.1 \mathrm{~mm}, 5 \mu \mathrm{m})\end{array}$ & $0.25 \%$ aqueous acetic acid and methanol & [192] \\
\hline 3 & 1 and 19 & HPLC-MS & $\begin{array}{l}\mathrm{C}_{18} \\
(4.0 \mathrm{~mm} \times 200 \mathrm{~mm}, 5 \mu \mathrm{m})\end{array}$ & $\begin{array}{l}\text { Acetonitrile with } 0.1 \% \text { acetic acid and } 0.1 \% \\
\text { acetic acid }\end{array}$ & [119] \\
\hline 4 & $1,2,3,8$ and 12 & HPLC-UV & $\begin{array}{l}\text { Zorbax SB-C18 } \\
(250 \mathrm{~mm} \times 4.6 \mathrm{~mm}, 5 \mu \mathrm{m})\end{array}$ & Water with $0.1 \%$ acetic acid and methanol & [59] \\
\hline 5 & $19,21,29$ and 30 & HPLC-DAD & $\begin{array}{l}\text { Eclipse XDB- } \mathrm{C}_{8} \\
(4.6 \mathrm{~mm} \text { i.d. } \times 150 \mathrm{~mm})\end{array}$ & Methanol and water with $1 \%$ formic acid & [110] \\
\hline 6 & $1,6,13,19,21,29,30,40,48,54,58$ and 67 & HPLC-UV & $\begin{array}{l}\text { Waters symmetry C18 } \\
(150 \times 4.6 \mathrm{~mm}, 5 \mu \mathrm{m})\end{array}$ & $0.25 \%$ aqueous acetic acid and methanol & [193] \\
\hline 7 & $\begin{array}{l}1,13,19,20,21,27,29,30,31,39, E-40, Z-40,47,53,54,56 \\
58,60,61 \text { and } 62\end{array}$ & HPLC-DAD-MS & $\begin{array}{l}\text { Alltima C18 } \\
(4.6 \mathrm{~mm} \times 250 \mathrm{~mm}, 5 \mu \mathrm{m})\end{array}$ & $0.5 \%$ acetic acid in water and acetonitrile & [194] \\
\hline 8 & $21,19,48,39,62$ & HPLC-MS $^{\mathrm{n}}$ & $\begin{array}{l}\text { Eclipse XDB-C }{ }_{18} \\
(4.6 \mathrm{~mm} \times 150 \mathrm{~mm}, 5 \mu \mathrm{m})\end{array}$ & $\begin{array}{l}0.25 \% \text { acetic acid and methanol (containing } \\
0.25 \% \text { acetic acid) }\end{array}$ & {$[195,196]$} \\
\hline 9 & $1,13,19,20,21,27,29,30,39, E-40$ and $Z-40$ & HPLC-ESI-MS & $\begin{array}{l}\text { Alltima C18 } \\
(4.6 \mathrm{~mm} \times 250 \mathrm{~mm}, 5 \mu \mathrm{m})\end{array}$ & Water and acetonitrile & [197] \\
\hline 10 & 1, 42 and 6,7-di-hydroxyligustilide & HPLC-DAD & $\begin{array}{l}\text { Shinwa-ODS } \\
(250 \mathrm{~mm} \times 4.6 \mathrm{~mm}, 5 \mu \mathrm{m})\end{array}$ & Methanol and $0.1 \%$ acetic acid & [198] \\
\hline 11 & $1,19,39,40$ and 67 & RP-HPLC-DAD & $\begin{array}{l}\text { Grace Smart RP C } 18 \\
(250 \mathrm{~mm} \times 4.6 \mathrm{~mm}, 5 \mu \mathrm{m})\end{array}$ & Acetonitrile and $0.1 \%$ phosphoric acid & [119] \\
\hline 12 & 19 and 21 & HPLC-DAD & $\begin{array}{l}\text { Zorbax SB-C } 18 \\
(4.6 \mathrm{~mm} \times 250 \mathrm{~mm}, 5 \mu \mathrm{m})\end{array}$ & Acetonitrile and $1 \%$ acetic acid & [200] \\
\hline 13 & $1,2,12,19,29,30$ and 40 & HPLC-DAD & $\begin{array}{l}\text { Alltima- } \mathrm{C}_{18} \\
(250 \mathrm{~mm} \times 4.6 \mathrm{~mm}, 5 \mu \mathrm{m})\end{array}$ & $0.2 \%$ aqueous formic acid and acetonitrile & [201] \\
\hline
\end{tabular}




\section{2. $G C-M S$}

Nowadays, modern sample preparation techniques in analytical chemistry are characterized by simplification, miniaturization, high enrichment and minimization of sample and solvent amounts. The volatile compounds in CX are recognized as an important part for its pharmacological activities [14]. For the analysis of the volatile compounds, some publications are available using GC-MS following steam distillation extraction, SFE, and other extraction methods [206]. Representative GC-MS methods developed for the chemical analysis of CX are summarized in Table 7 [20,59,108,207-213]. According to different chromatographic conditions, several or even hundreds of components of CX can be simultaneously determined by this method. The column temperature commonly uses programmed temperatures.

Among these methods, GC-MS sometimes was used to analyze and identify the volatile chemical components of $\mathrm{CX}$ by the combination of chemometric local resolution techniques such as subwindow factor analysis (SFA), orthogonal projection resolution (OPR) [209], heuristic evolving latent projections (HELP), the overall volume integration method [212], and other methods. With the help of chemometric approaches, the purity of chromatographic peaks can be identified. The combination of GC-MS with chemometric local resolution methods could greatly improve the chromatographic separation ability by means of mathematical approaches, indicating the reliability and practicability of these combined techniques. A headspace solid-phase microextraction (HS-SPME) method followed by GC-MS was described and a comparison between HS-SPME-GC-MS and steam distillation (SD)-GC-MS methods was made [213]. The results showed that HS-SPME method could achieve comparable results ( 73 compounds) with those by SD method (about 50 compounds), using much less sample, shorter extraction time and a simpler procedure. Additionally, effective components 19/20 and 40 were screened and identified using a cell membrane chromatography (CMC) and a simple capillary GC-MS method [14,206]. The volatile oils of $23 \mathrm{CX}$ samples from four different regions were analyzed by comprehensive two-dimensional GC/time-of-flight/MS (GC-TOF-MS) [214]. The group-type separation of four terpenoids (monoterpenes, oxygenated monoterpenes, sesquiterpenes, and oxygenated sesquiterpenes) and phthalides was well accomplished based on a DB-Petro $\times$ DB-17 column system. With the MS library search, 215 compounds were tentatively identified based on the NIST database and 43 compounds of them were confirmed. Twenty three samples were apparently classified into four groups by partial least square-discriminant analysis (PLS-DA). All the results indicated that phthalides exerted a great influence on the chemical and biochemical classifications of CX. 
Table 7. GC-MS methods developed for the chemical analysis of CX.

\begin{tabular}{|c|c|c|c|c|c|}
\hline No. & Analytes & Detection mode & Stationary phase & Temperature & Ref. \\
\hline 1 & $19,39,40,47,48$ and senkyunolide & HP 5890 SERIES I GC & $\begin{array}{l}\text { Gross-Linked Methyl Silicone } \\
\text { Gum Phase }(25 \mathrm{~m} \times 0.2 \mathrm{~mm})\end{array}$ & $\begin{array}{l}\text { Column: } 80^{\circ} \mathrm{C} \text {; injector and detector: } \\
250{ }^{\circ} \mathrm{C} \text {; source: } 200^{\circ} \mathrm{C} \text {; interface: } 280{ }^{\circ} \mathrm{C}\end{array}$ & [207] \\
\hline 2 & $19,20,21,22,27,29,30,39,40$ and 48 & $\begin{array}{l}\text { HP6890 (GC) and a mass } \\
\text { selective detector (HP5973) }\end{array}$ & $\begin{array}{l}\text { HP-5 MS capillary column } \\
(30 \mathrm{~m} \times 0.25 \mathrm{~mm}, 0.25 \mu \mathrm{m})\end{array}$ & $\begin{array}{l}\text { Column: } 80^{\circ} \mathrm{C}-280{ }^{\circ} \mathrm{C} \text {; injector: } 250{ }^{\circ} \mathrm{C} \text {; } \\
\text { source: } 250^{\circ} \mathrm{C}\end{array}$ & {$[59]$} \\
\hline 3 & 45 components were identified. & HP5988A GC-MS & $\begin{array}{l}\text { SE-30 capillary column } \\
(30 \mathrm{~m} \times 0.25 \mathrm{~mm}, 0.25 \mu \mathrm{m})\end{array}$ & Column: $90^{\circ} \mathrm{C}-250{ }^{\circ} \mathrm{C}$; injector: $260^{\circ} \mathrm{C}$ & [208] \\
\hline 4 & $\begin{array}{l}\text { About } 127 \text { chemical components be } \\
\text { separated and } 81 \text { of them identified. }\end{array}$ & $\begin{array}{l}\text { Shimadzu } \\
\text { GC-17A }\end{array}$ & $\begin{array}{l}\text { OV-17 capillary column } \\
(30 \mathrm{~m} \times 0.25 \mathrm{~mm})\end{array}$ & $\begin{array}{l}\text { Column: } 40^{\circ} \mathrm{C}-230{ }^{\circ} \mathrm{C} \text {; injector: } 250{ }^{\circ} \mathrm{C} \text {; } \\
\text { source: } 230^{\circ} \mathrm{C}\end{array}$ & [209] \\
\hline 5 & 59 components were identified. & Agilent 6890N 5973N GC-MS & $\begin{array}{l}\text { HP- } 1 \text { capillary column } \\
(30 \mathrm{~m} \times 0.25 \mathrm{~mm})\end{array}$ & $\begin{array}{l}\text { Column: } 40^{\circ} \mathrm{C}-230{ }^{\circ} \mathrm{C} \text {; injector: } 280{ }^{\circ} \mathrm{C} \text {; } \\
\text { source: } 230^{\circ} \mathrm{C} \text {; interface: } 280^{\circ} \mathrm{C}\end{array}$ & [210] \\
\hline 6 & 19 and 21 & Shimadzu GC-14B & $\begin{array}{l}\text { SE-54 quartz capillary column } \\
(50 \mathrm{~m} \times 0.2 \mathrm{~mm})\end{array}$ & $\begin{array}{l}\text { Column: } 240^{\circ} \mathrm{C} \text {; injector and } \\
\text { detector: } 280^{\circ} \mathrm{C}\end{array}$ & [211] \\
\hline 7 & $\begin{array}{l}52 \text { volatile chemical components were } \\
\text { determined. }\end{array}$ & Agilent 6890N 5973N GC-MS & $\begin{array}{l}\text { HP-5MS capillary column } \\
(30 \mathrm{~m} \times 0.25 \mathrm{~mm})\end{array}$ & $\begin{array}{l}\text { Column: } 60^{\circ} \mathrm{C}-250{ }^{\circ} \mathrm{C} \text {; injector: } 250{ }^{\circ} \mathrm{C} \text {; } \\
\text { source: } 230^{\circ} \mathrm{C} \text {; interface: } 280{ }^{\circ} \mathrm{C}\end{array}$ & [212] \\
\hline 8 & 73 compounds were identified. & HP 5973 GC-MSD & $\begin{array}{l}\text { HP-INNOWAX } \\
(30 \mathrm{~m} \times 0.25 \mathrm{~mm}, 0.25 \mu \mathrm{m})\end{array}$ & $\begin{array}{l}\text { Column: } 50^{\circ} \mathrm{C}-210{ }^{\circ} \mathrm{C} \text {; injector: } 250{ }^{\circ} \mathrm{C} \text {; } \\
\text { source: } 250{ }^{\circ} \mathrm{C} \text {; interface: } 280{ }^{\circ} \mathrm{C}\end{array}$ & [213] \\
\hline 9 & 62 components were identified. & Trace MS 2000 GC-MS & $\begin{array}{l}\text { DB-5 capillary column } \\
(0.25 \mathrm{~mm} \times 30 \mathrm{~m}, 0.25 \mu \mathrm{m})\end{array}$ & $\begin{array}{l}\text { Column: } 50{ }^{\circ} \mathrm{C}-240{ }^{\circ} \mathrm{C} \text {; injector: } 270{ }^{\circ} \mathrm{C} \text {; } \\
\text { source: } 200{ }^{\circ} \mathrm{C} \text {; interface: } 250{ }^{\circ} \mathrm{C}\end{array}$ & {$[20]$} \\
\hline 10 & 52 compounds were identified. & HP 6890 N GC & $\begin{array}{l}\mathrm{HP}-5 \\
(30 \mathrm{~m} \times 0.32 \mathrm{~mm}, 0.25 \mu \mathrm{m})\end{array}$ & $\begin{array}{l}\text { Column: } 40^{\circ} \mathrm{C}-100^{\circ} \mathrm{C} \text {; injector: } 260^{\circ} \mathrm{C} \text {; } \\
\text { source: } 200^{\circ} \mathrm{C} \text {; interface: } 220^{\circ} \mathrm{C}\end{array}$ & {$[108]$} \\
\hline
\end{tabular}




\section{3. $C E$}

$\mathrm{CE}$ is increasingly recognized as an important analytical separation technique because of its speed, efficiency, reproducibility, ultra-small sample volume, less consumption of solvent and ease of clearing up the contaminants [215]. CZE, which was first reported in 1981 [216], is an important model of CE. The content of compound $\mathbf{1}$ in CX was easily determined within 15 min with no pretreatment and interference by CZE [42]. Because of the complex constituents of CX, the column is easily polluted by the volatile oil, saccharide, and other components of this herb when detected by HPLC, thus leading to shortened life expectancy. However, those shortcomings can be overcome by HPCE. In recent years, HPCE has been developed as a powerful multi-dimensional separation technique [217], which is a hybrid technique that combines the advantages of HPLC and CE, also one of the very suitable analysis techniques for the multi-components analysis of TCM. This method has been recorded by the appendix of Chinese Pharmacopoeia (the 2005 edition), indicating it has become an official analysis technique for TCMs. The chemical composition spectrum of aqueous solution of CX was analyzed by HPCE, and compound 67 was identified [218]. However, in practice, when capillary electrochromatography (CEC) is used without pressure, often on a commercial CE instrument, there are problems associated with bubble formation in CEC, occurring initially in the unpacked section of the capillary, probably as a result of differences in velocity of the liquid eluent between the packed and unpacked sections of the capillary and column dry out [219]. The use of supplementary pressure has proved effective to stabilize the flow conditions. Compared with traditional HPLC and CE, the mobile phase in the pressurized CE (pCEC) system is driven by a pressurized flow and an electroosmotic flow simultaneously, reducing band broadening and improving separation efficiency. Now pCEC has become an attractive technique for pharmaceutical analysis because of its combination of the inherent advantages of two major separation techniques [220,221]. In addition, with amperometric detection (AD), CE-AD affords high sensitivity and good selectivity for electroactive species. Bioactive ingredients of $C X$ including compounds $\mathbf{1}, \mathbf{2}, \mathbf{3}, \mathbf{4}, \mathbf{5}, \mathbf{6}, \mathbf{8}$, and 12 were determined by CE-AD as marker compounds, and the characteristic "electrochemical profiles" of CX was studied $[60,215]$.

\section{Fingerprinting}

Fingerprint analysis is considered as one of the most powerful approaches in quality control of TCMs. Conventional research focuses mainly on the determination of the most active components, while fingerprinting can offer characterization of a complex system with a degree of quantitative reliability, which is consistent with the theory that all the components, not just the few active compounds. in TCMs are held to be responsible for the beneficial effects Furthermore, fingerprint analysis can be used for identifying and assessing the authenticity, stability, plant anatomy, geographical origins, and harvest time of medicinal herbs. Nowadays, chromatographic techniques have been widely used in fingerprint analysis for quality control of CX, such as HPLC [222,223], HPCE [218,224], pCEC [221], hydrophilic interaction chromatography (HILIC)-RPLC [30], ${ }^{1}$ H-NMR-HPLC [225], HPLC-DAD-MS [226], and GC-MS [227,228]. 
Fingerprint similarity analysis of CX from three producing areas (Jiangxi, Sichuan, and Guangdong province of China) was studied by HPLC, and the peak areas of fifteen common components in their chromatograms were used to construct the fingerprints [222]. Principal component analysis (PCA) was applied to the fingerprint. It showed that the original region will cause significant differences. A vector of differences was defined between two fingerprints. The scalar mean of the different vector was taken as a statistic and both the $t$-test and Bayesian hypothesis testing were implemented to provide a one-to-one comparison of the fingerprints. Compared with PCA, correlation coefficient and vector cosine, the new method offers a better differentiation of the similarity or difference between the fingerprints from same sample of CX. Xie et al. [221] successfully developed a characteristic fingerprint by using pCEC and HPLC simultaneously for identifying raw CX herb. Two mathematical methods, correlation coefficient and the included angle cosine were applied for quantitative studies of the similarity of 10 batches of CX. Characteristics of pCEC and HPLC methods used to develop TCM fingerprint were summarized. It was proved that $\mathrm{pCEC}$ could be used as an alternative or supplementary technique for the development of fingerprint analysis of TCM through HPLC procedures. A binary chromatographic fingerprint analysis using HILIC and RPLC was developed to gain more chemical information about polar compounds and weakly polar compounds, which was used to construct a chromatographic fingerprint of CX [30]. Data from the analysis of CX samples were processed with similarity analysis, with correlation coefficients and congruence coefficients. To compare the quality of 14 samples, the change trend of similarity among the 14 samples calculated with four different methods (correlation coefficients and congruence coefficients with median and average data) was described. The production area of CX was relatively localized, mainly in Sichuan Province, and there was no obvious difference in the quality of samples from several areas in Sichuan Province, e.g., samples from Peng region and Guan region showed quality consistent with those from a genuine production area (Dujiangyan region). The technique of ${ }^{1} \mathrm{H}-\mathrm{NMR}$ and HPLC fingerprinting analysis is rapid, reproducible and stable with time for the authentication of medicinal plant species [229,230]. The ${ }^{1} \mathrm{H}-\mathrm{NMR}$ fingerprints of fractionated non-polar extracts (control substance for a plant drug, CSPD A) from CX of seven specimens from different sources were measured on Fourier Transform-NMR spectrometer and assigned by comparing them with the ${ }^{1} \mathrm{H}-\mathrm{NMR}$ spectra of the isolated pure compounds. The ${ }^{1} \mathrm{H}-\mathrm{NMR}$ fingerprints showed exclusively characteristic resonance signals of the major special constituents of the plant. Although the differences in the relative intensity of the ${ }^{1} \mathrm{H}-\mathrm{NMR}$ signals due to a discrepancy in the ratio of the major constituents among these samples could be confirmed by HPLC analysis, the general features of the ${ }^{1} \mathrm{H}-\mathrm{NMR}$ fingerprint established for an authentic sample of the rhizomes of CX exhibited exclusive data from those special compounds and could be used for authenticating CX species [225].

In the study of TCM fingerprints, the combination of chromatography and MS has better specificity than a single chromatography, and provides a more reliable basis for quality control. All the fingerprint results showed that place of origin significantly influenced the kinds and content of components in crude TCMs, and hence affected their quality. 


\section{Conclusions}

We have summarized the recent progress in the chemical analysis of CX. Organic acids, phthalides, alkaloids, polysaccharides, ceramides and cerebrosides are believed to be the main bioactive constituents of CX. A variety of technologies have been used for the qualitative and quantitative analyses of these compounds in CX and its preparations. Currently, HPLC, HPLC-MS and GC-MS are mostly used for CX analysis. However, the qualitative information using HPLC-MS under multiple reaction monitoring (MRM) mode is not enough to elucidate the structure. Though in the full-scan mode this information can be obtained, the lack of sensitivity and the lack of compound databases and mass-spectral libraries may be obstructive to the qualitative analysis. So far, no satisfactory method has been reported for the simultaneous analysis of all the major components of CX. A novel approach to chromatographic separation is ultra performance liquid chromatography (UPLC), which is based on the use of columns with smaller packing and operated at higher pressures [231]. Compared with traditional HPLC, UPLC provides a higher peak capacity, greater resolution, increased sensitivity and higher speed of analysis. When coupled with orthogonal quadrupole time-of-flight mass spectrometry, UPLC-Q-TOF-MS provides several advantages in the separation of complicated samples such as the field of TCMs, metabolomics, and drug metabolism [232,233]. The advantages of its higher resolution and the accuracy in mass measurements make it a powerful tool for identification of the analytes, therefore, UPLC-Q-TOF-MS facilitates the rapid and sensitive characterization of CX extracts even when pure standards are not available. Furthermore, MRM using tandem quadrupole mass spectrometry (TQ-MS), which monitors both the specific precursor ions and product ions of each metabolite, is a standard technique in targeted metabolomics, as it enables high sensitivity, reproducibility and a broad dynamic range. By UPLC-TQ-MS analysis, more analytes and metabolites can be quantified in each crude herb extract or its biological sample [234,235]. Given these advantages, we can expect that they will find applications in many aspects of CX analyses, such as chemical fingerprinting, which globally addresses the organic acids, phthalides, alkaloids and other compounds; the simultaneous determination of most major organic acids, phthalides and alkaloids for the quality control. All these studies are critically important for the quality control of CX, so as to ensure its safety and efficacy in clinical applications. What is more, the characteristics of UPLC-Q-TOF-MS, UPLC-TQ-MS, and other techniques such as UPLC-high definition mass spectrometry (HDMS) will be the method of choice for the in vivo metabolism, metabolomics and pharmacokinetic studies of CX.

\section{Acknowledgments}

Financial support from the following sources is gratefully acknowledged: National Key Technology R\&D Program (2008BAI51B01), the Specialized Research Fund for the Doctoral Program of Higher Education of China (20113237110010), Graduate Innovation Project of Jiangsu Province (CXZZ12_0627), National Natural Science Foundation of China (30873235), 2009' Program for New Century Excellent Talents by the Ministry of Education (NCET-09-0163), Key Research Project in Basic Science of Jiangsu College and University (06KJA36022, 07KJA36024, 10KJA360039, 12KJA360002), 2009' Program for Excellent Scientific and Technological Innovation Team of Jiangsu 
Higher Education. This research was also financially supported by Construction Project for Jiangsu Engineering Center of Innovative Drug from Blood-conditioning TCM Formulae, and A Project Funded by the Priority Academic Program Development of Jiangsu Higher Education Institutions (ysxk-2010).

\section{References}

1. The State Pharmacopoeia Commission of the People's Republic of China. Chinese Pharmacopoeia; Chemical Industry Press: Beijing, China, 2010; Volume 1, p. 38.

2. The State Pharmacopoeia Commission of the People's Republic of China. Chinese Pharmacopoeia; Chemical Industry Press: Beijing, China, 2005; Volume 1, p. 28.

3. Wagner, H.; Bauer, R.; Melchart, D.; Xiao, P.G.; Staudinger, A. Chromatographic Fingerprint Analysis of Herbal Medicines: Thin-layer and High Performance Liquid Chromatography of Chinese Drugs, 2nd ed.; Springer Wien New York: Berlin, Germany, 2011; Volume 1, pp. 181-190.

4. The Compile Commission of Zhonghua Bencao of the State Administration of TCM of China. Zhonghua Bencao; Shanghai Science and Technology Press: Shanghai, China, 1999; Volume 5, p. 976.

5. Song, P.S.; Ma, X.; Zhang, B.C.; Wang, Q.Z. Textual research and historical evolution of Xiongqiong (Chuanxiong). China J. Chin. Mat. Med. 2000, 25, 434-446.

6. Zhang, Y.S. Yixue Qiyuan; People's Medical Publishing House: Beijing, China, 1978; p. 63.

7. Ramalingam, M.; Yong-Ki, P. Free radical scavenging activities of Cnidium officinale Makino and Ligusticum chuanxiong Hort. methanolic extracts. Pharmacogn. Mag. 2010, 6, 323-330.

8. Li, H.X.; Ding, M.Y.; Lü, K.; Yu, J.Y. Determination of the active ingredients in Chuanxiong by HPLC, HPLC-MS, and EI-MS. J. Liq. Chromatogr. R. T. 2001, 24, 2017-2031.

9. Masaru, K.; Hiroshi, M. Structures of three new ligustilide derivatives from Ligusticum wallichii. Chem. Pharm. Bull. (Tokyo) 1987, 35, 4789-4792.

10. Masaru, K.; Miyuki, F.; Hiroshi, M. Studies on the constituents of umbelliferae plants. XV.1) constituents of Cnidium officinale: Occurrence of pregnenolone, coniferylferulate and hydroxyphthalides. Chem. Pharm. Bull. (Tokyo) 1987, 35, 1427-1433.

11. Lee, S.H.; Choi, H.W.; Sung, J.S.; Bang, J.W. Inter-genomic relationships among three medicinal herbs: Cnidium officinale, Ligusticum chuanxiong and Angelica polymorpha. Genes Genom. 2010, 32, 95-101.

12. Park, Y.K. The study on antioxidative effects and quality comparison of Ligusticum chuanxiong and Cnidium officinale (1). Korean J. Herbol. 1998, 13, 103-108.

13. Lee, H.W.; Cho, H.G.; Park, Y.K. The study on antioxidative effects and quality comparison of Ligusticum chuanxiong and Cnidium officinale (2). Vascular relaxant effect of Cnidii rhizome and Cnidii rhizome-Angelicae radix compound. Korean J. Herbol. 1999, 14, 55-60.

14. Jeong, J.B.; Ju, S.Y.; Park, J.H.; Lee, J.R.; Yun, K.W.; Kwon, S.T.; Lim, J.H.; Chung, G.Y.; Jeong, H.J. Antioxidant activity in essential oils of Cnidium officinale makino and Ligusticum chuanxiong Hort and their inhibitory effects on DNA damage and apoptosis induced by ultraviolet B in mammalian cell. Cancer Epidemiol. 2009, 33, 41-46. 
15. Chen, X.F.; Ding, D.R.; Huang, W.X.; Liu, S.R.; Liu, S.X. The growth and development characteristics of Chuanxiong. China J. Chin. Mat. Med. 1997, 22, 527-574.

16. Li, S.L.; Lin, G.; Tam, Y.K. Time-course accumulation of main bioactive components in the rhizome of Ligusticum chuanxiong. Planta Med. 2006, 72, 278-280.

17. Zhang, Y.; Fan, Q.J.; Zheng, S.L.; Zhou, H.; Yuan, J.C.; Ma, Y.Y.; Jiang, G.H. The effects of additional fertilizer in spring on the content of chuanxiong production, ferulic acid and total alkaloid. China J. Chin. Mat. Med. 2008, 33, 1944-1947.

18. Hou, J. Quality evaluating of germplasm resources of Chuanxiong in different producing areas. Master Thesis, Chengdu University of TCM, Chengdu, China, 2007.

19. Shi, X.J.; Chen, L.; Peng, C. Comparative study of chemical composition of chuanxiong from different commodities specifications. J. Sichuan Tradit. Chin. Med. 2011, 29, 58-61.

20. Wu, Q.; Yang, X.W. GC-MS analysis of essential oil from rhizomes of Ligusticum chuanxiong cultivated in GAP base for Chinese medicinal materials of China. China J. Chin. Mat. Med. 2008, 33, 276-280.

21. Gao, X.M. Traditional Chinese Pharmacy; China Press Traditional Chinese Medicine: Beijing, China, 2006; p. 364.

22. Zhang, L.; Jiang, Y.R.; Guo, C.Y.; Wu, C.F.; Chen, K.J.; Yin, H.J. Effects of active components of Red Paeonia and Rhizoma chuanxiong on angiogenesis in atherosclerosis plaque in rabbits. Chin. J. Integr. Med. 2009, 15, 359-364.

23. Liang, M.J.; He, L.C.; Yang, G.D. Screening, analysis and in vitro vasodilatation of effective components from Ligusticum chuanxiong. Life Sci. 2005, 78, 128-133.

24. Li, M.; Handa, S.; Ikeda, Y.; Goto, S. Specific inhibiting characteristics of tetramethylpyrazine, one of the active ingredients of the Chinese herbal medicine "Chuanxiong", on platelet thrombus formation under high shear rates. Thromb. Res. 2001, 104, 15-28.

25. Chen, K.J.; Chen, K. Ischemic stroke treated with Ligusticum chuanxiong. Chin. Med. J. (Engl.) 1992, 105, 870-873.

26. Yang, X.; Zeng, X.; Wu, T. Chuanxiong preparations for preventing stroke. Cochrane Database Syst. Rev. 2010, doi:10.1002/14651858.CD006765.pub2.

27. Chan, S.S.; Jones, R.L.; Lin, G. Synergistic interaction between the Ligusticum chuanxiong constituent butylidenephthalide and the nitric oxide donor sodium nitroprusside in relaxing rat isolated aorta. J. Ethnopharmacol. 2009, 122, 308-312.

28. Hou, Y.Z.; Zhao, G.R.; Yang, J.; Yuan, Y.J.; Zhu, G.G.; Hiltunen, R. Protective effect of Ligusticum chuanxiong and Angelica sinensis on endothelial cell damage induced by hydrogen peroxide. Life Sci. 2004, 75, 1775-1786.

29. Hou, Y.Z.; Zhao, G.R.; Yuan, Y.J.; Zhu, G.G.; Hiltunen, R. Inhibition of rat vascular smooth muscle cell proliferation by extract of Ligusticum chuanxiong and Angelica sinensis. J. Ethnopharmacol. 2005, 100, 140-144.

30. Jin, Y.; Liang, T.; Fu, Q.; Xiao, Y.S.; Feng, J.T.; Ke, Y.X.; Liang, X.M. Fingerprint analysis of Ligusticum chuanxiong using hydrophilic interaction chromatography and reversed-phase liquid chromatography. J. Chromatogr. A 2009, 1216, 2136-2141. 
31. Lu, Y.; Hu, Y.L.; Kong, X.F.; Wang, D.Y. Selection of component drug in activating blood flow and removing blood stasis of Chinese herbal medicinal formula for dairy cow mastitis by hemorheological method. J. Ethnopharmacol. 2008, 116, 313-317.

32. Shu, D.; He, J.; Chen, J. Neuroprotective effects and mechanisms of Chuanxiong Chatiao pulvis against MPTP-induced dopaminergic neurotoxicity in mice model of Parkinson's disease. China J. Chin. Mat. Med. 2009, 34, 2494-2497.

33. Lin, Y.L.; Wang, G.J.; Huang, C.L.; Lee, Y.C.; Liao, W.C.; Lai, W.L.; Lin, Y.J.; Huang, N.K. Ligusticum chuanxiong as a potential neuroprotectant for preventing serum deprivation-induced apoptosis in rat pheochromocytoma cells: functional roles of mitogen-activated protein kinases. J. Ethnopharmacol. 2009, 122, 417-423.

34. Or, T.C.; Yang, C.L.; Law, A.H.; Li, J.C.; Lau, A.S. Isolation and identification of anti-inflammatory constituents from Ligusticum chuanxiong and their underlying mechanisms of action on microglia. Neuropharmacology 2011, 60, 823-831.

35. Li, Y.; Xu, C.; Zhang, Q.; Liu, J.Y.; Tan, R.X. In vitro anti-Helicobacter pylori action of 30 Chinese herbal medicines used to treat ulcer diseases. J. Ethnopharmacol. 2005, 98, 329-333.

36. Lee, T.F.; Lin, Y.L.; Huang, Y.T. Studies on antiproliferative effects of phthalides from Ligusticum chuanxiong in hepatic stellate cells. Planta Med. 2007, 73, 527-534.

37. Chor, S.Y.; Hui, A.Y.; To, K.F.; Chan, K.K.; Go, Y.Y.; Chan, H.L.; Leung, W.K.; Sung, J.J. Anti-proliferative and pro-apoptotic effects of herbal medicine on hepatic stellate cell. J. Ethnopharmacol. 2005, 100, 180-186.

38. Yuan, J.F.; Zhang, Z.Q.; Fan, Z.C.; Yang, J.X. Antioxidant effects and cytotoxicity of three purified polysaccharides from Ligusticum chuanxiong Hort. Carbohydr. Polym. 2008, 74, $822-827$.

39. Wu, J.G.; Wei, Y.J.; Ran, X.; Zhang, H.; Nian, H.; Qin, L.P. Inhibitory effects of essential oil from rhizomes of Ligusticum chuanxiong on hypertrophic scarring in the rabbit ear model. Pharm. Biol. 2011, 49, 764-769.

40. Zeng, Z.D.; Liang, Y.Z.; Chau, F.T.; Chen, S.; Daniel, M.K.W.; Chan, C.O. Mass spectral profiling: An effective tool for quality control of herbal medicines. Anal. Chim. Acta 2007, 604, 89-98.

41. Liang, Y.Z.; Xie, P.S.; Chau, F. Chromatographic fingerprinting and related chemometric techniques for quality control of traditional Chinese medicines. J. Sep. Sci. 2010, 33, 410-421.

42. Ji, S.G.; Chai, Y.F.; Wu, Y.T.; Yin, X.P.; Liang, D.S.; Xu, Z.X.; Li, X. Determination of ferulic acid in Angelica sinensis and Chuanxiong by capillary zone electrophoresis. Biomed. Chromatogr. 1999, 13, 333-334.

43. Wang, W.X.; Gu, M.; Jiang, X.G.; Gu, Z.L.; Fan, P.S. Studies on chemical constituents of Ligusticum chuanxiong. Chin. Tradit. Herb. Drugs 2002, 33, 4-5.

44. Wang, P.S.; Gao, X.L.; Fushan, A.B.; Guanhou, D.Z. The chemical composition of traditional Chinese medicine Chuanxiong-Six phenolic compounds. Chin. Tradit. Herb. Drugs 1985, 16, 45-47.

45. Beijing Institute on the Pharmaceutical Industry. Chemical research of the constituents of Chuanxiong. Pharm. Bull. 1980, 15, 471. 
46. Beijing Institute on the Pharmaceutical Industry. The effective constituents study of Chuanxiong. Pharm. Bull. 1979, 14, 670-675.

47. Wang, P.S.; Gao, X.L.; Fushan, A.B.; Guanhou, D.Z. The chemical composition of traditional Chinese medicine Chuanxiong-A terpenoid. Chin. Tradit. Herb. Drugs 1985, 16, 30-32.

48. Ke, R.T.; Zeng, G.F. The chemical composition study of Chuanxiong. Acta Chim. Sin. 1957, 23, 246.

49. Cao, F.Y.; Liu, W.X.; Wen, Y.S.; He, Z.R.; Qin, W.J. The chemical composition study of Chuanxiong. Chin. Tradit. Herb. Drugs 1983, 14, 1-3.

50. Qian, F.; Yan, E.C. Qualitative and quantitative analysis of ferulic acid in Chuanxiong by TLC scanning method. Chin. Tradit. Pat. Med. 1990, 12, 9-10.

51. Wang, F.; Kuang, W.H. RP-HPLC determination of ferulic acid of Ligusticum chuanxiong Hort from different areas. Chin. J. Mod. Appl. Pharm. 2002, 19, 310-311.

52. Sheng, Y.X.; Li, L.; Wang, Q.; Guo, H.Z.; Guo, D.A. Simultaneous determination of gallic acid, albiflorin, paeoniflorin, ferulic acid and benzoic acid in Si-Wu decoction by high-performance liquid chromatography DAD method. J. Pharm. Biomed. Anal. 2005, 37, 805-810.

53. Zhang, T.H.; Yang, X.L.; Zhang, P.; Zhu, M.; He, Z.G.; Bi, K.S. Determination of ferulic acid in rat plasma by liquid chromatography-tandem mass spectrometry method: application to a pharmacokinetic study. Anal. Lett. 2009, 42, 2157-2169.

54. Li, L.J.; Feng, J.; Cheng, H.; Chen, Q.F.; Zhong, Z.H.; Kong, H.X.; Wu, J.L. Separation and determination of salicylic acid, cinnamic acid, ferulic acid and vanillic acid with sample stacking-non-aqueous electrophoresis. Chin. J. Anal. Chem. 2007, 35, 401-404.

55. Xian, D.L.; Huang, K.L.; Hu, W.G.; Xiao, J.Y.; Jiao, F.P. Evaluation of ferulic acid-biomembrane interaction by liposome electrokinetic chromatography. Chin. J. Anal. Chem. 2007, 35, 1521-1524.

56. Kong, L.; Yu, Z.Y.; Bao, Y.M.; Su, X.Y.; Zou, H.F.; Li, X. Screening and analysis of an antineoplastic compound in Rhizoma Chuanxiong by means of in vitro metabolism and HPLC-MS. Anal. Bioanal. Chem. 2006, 386, 264-274.

57. Li, H.X.; Ding, M.Y.; Yu, J.Y. Separation and identification of the phthalic anhydride derivatives of Ligusticum Chuanxiong Hort by GC-MS, TLC, HPLC-DAD, and HPLC-MS. J. Chromatogr. Sci. 2002, 40, 156-161.

58. Li, F.; Cao, Q.E.; Ding, Z. Separation and determination of three phenylpropanoids in the traditional Chinese medicine and its preparations by capillary electrophoresis. J. Chromatogr. Sci. 2007, 45, 354-359.

59. Zhao, Y.X.; Ding, M.Y.; Liu, D.L. Phenolic acids analysis in Ligusticum chuanxiong using HPLC. J. Chromatogr. Sci. 2005, 43, 389-393.

60. Antolovich, M.; Prenzler, P.D.; Robards, K.; Ryan, D. Sample preparation in the determination of phenolic compounds in fruits. Analyst 2000, 125, 989-1009.

61. Huang, W.Y.; Sheu, S.J. Separation and identification of the organic acids in Angelicae Radix and Ligustici Rhizoma by HPLC and CE. J. Sep. Sci. 2006, 29, 2616-2624.

62. Tian, S.; Nakamura, K.; Kayahara, H. Analysis of phenolic compounds in white rice, brown rice, and germinated brown rice. J. Agric. Food Chem. 2004, 52, 4808-4813. 
63. Goncalves, J.; Mendes, B.; Silva, C.L.; Camara, J.S. Development of a novel microextraction by packed sorbent-based approach followed by ultrahigh pressure liquid chromatography as a powerful technique for quantification phenolic constituents of biological interest in wines. J. Chromatogr. A 2012, 1229, 13-23.

64. Lü, G.; Cheng, S.; Chan, K.; Leung, K.S.; Zhao, Z. Determination of free ferulic acid and total ferulic acid in Chuanxiong by high-performance liquid chromatography for quality assessment. China J. Chin. Mat. Med. 2010, 35, 194-198.

65. Li, Y.; Lu, D.G.; Lei, Y.Q.; Lei, P.; Liu, S.; Li, X.Z. Comparison of ferulic acid and paeoniflorin between traditional slice decoction and dispensing granule decoction of Siwu Tang. J. Chin. Med. Mat. 2008, 31, 125-128.

66. Xu, Z.M.; Ji, S.G. Separation and determination of ferulic acid in Chuanxiong by high performance capillary electrophoresis. J. Pharm. Pract. 1998, 16, 165-166.

67. Liu, Y.P.; Li, Z.L.; Zhang, T.M.; Ling, Y.K.; Wan, L. The determination of ferulic acid in Chuanxiong different parts by TLC scanning method. China J. Chin. Mat. Med. 1995, 20, 9-10.

68. Luo, L.; Guo, R.; Wu, H.; Zhang, A.H.; Qiu, L.Y.; Qian, Q.X. The effect of Paozhi on the content of ferulic acid in chuanxiong. J. Chin. Med. Mat. 1998, 21, 184-185.

69. Wang, W.X.; Gu, M.; Xu, X.Y.; Tang, L.H.; Gu, Z.L. The determination of ferulic acid in Chuanxiong by HPLC. Chin. Wild Plant Res. 2000, 19, 44-45.

70. Liu, Y.; Jia, M.R. Determination of Rhizoma Chuanxiong, Naixiong and Shanchuanxiong by RP-HPLC. West China J. Pharm. Sci. 2004, 19, 363-365.

71. Li, L.; Dou, C.J.; Yao, L. Determination of ferulic acid in Ligusticum chuanxiong by supercritical fluid $\mathrm{CO}_{2}$ extraction method and HPLC. Chem. Anal. Meterage 2006, 15, 42-45.

72. Zhu, L.B.; Zou, X.F. Determination of the contents of ferulic acid in Rhizoma Chuanxiong from different regions by HPLC. Heilongjiang Med. J. 2008, 21, 13-14.

73. Cai, D.F.; Zhang, Q.; Zou, Y.; Wang, J.C. Determination of the content of ferulic acid in Rhizoma Chuanxiong by RP-HPLC. J. Qiqihar Med. Coll. 2008, 29, 835-836.

74. Wang, M.W.; Zhang, Y.; Zhang, J.; Xiao, Y.Y.; Ma, Y.Y.; Jiang, G.H. Determination of the content of total ferulic acid in Rhizoma Chuanxiong by HPLC. West China J. Pharm. Sci. 2008, 23, 100-102.

75. Zhang, X.L. Determination of the content of ferulic acid in Chuanxiong by HPLC. Chin. Pharm. Aff. 2009, 23, 469-471.

76. Fu, X.Y.; Huang, Q.L. Comparative determination of ferulic acid in two kinds of Chuanxiong by HPLC and UPLC. J. Chin. Med. Mat. 2011, 34, 1070-1072.

77. Wang, X.M.; Jiao, L.; Liu, X.L.; Li, H. Quantitative ananlysis of ferulic acid in Ligusticum chuanxiong Hort. by near infrared diffuse reflectance spectroscopy. Chin. J. Pharm. Anal. 2011, 31, 1016-1019.

78. Tang, Y.P.; Duan, J.A.; Fan, X.S.; Shang, E.X.; Su, S.L.; Ding, A.W. Effects of aromatic acids on stimulating blood circulation and removing blood stasis. World Sci. Technol. 2008, 10, 38-42.

79. Hou, Y.Z.; Yang, J.; Zhao, G.R.; Yuan, Y.J. Ferulic acid inhibits vascular smooth muscle cell proliferation induced by angiotensin II. Eur. J. Pharmacol. 2004, 499, 85-90. 
80. Kobayashi, S.; Mimura, Y.; Naitoh, T.; Kimura, I.; Kimura, M. Chemical structure-activity of cnidium rhizome-derived phthalides for the competence inhibition of proliferation in primary cultures of mouse aorta smooth muscle cells. Jpn. J. Pharmacol. 1993, 63, 353-359.

81. Mathew, S.; Abraham, T.E. Ferulic acid: an antioxidant found naturally in plant cell walls and feruloyl esterases involved in its release and their applications. Crit. Rev. Biotechnol. 2004, 24, 59-83.

82. Lin, Z.H.; Zhu, D.N.; Yan, Y.Q.; Yu, B.Y. Neuroprotection by herbal formula FBD and its active compounds. Pharm. Biol. 2009, 47, 608-614.

83. Barone, E.; Calabrese, V.; Mancuso, C. Ferulic acid and its therapeutic potential as a hormetin for age-related diseases. Biogerontology 2009, 10, 97-108.

84. Madhujith, T.; Shahidi, F. Antioxidant and antiproliferative potential of pearled barley (Hordeum vulgarae). Pharm. Biol. 2008, 46, 88-95.

85. Chawla, A.S.; Singh, M.; Murthy, M.S.; Gupta, M.; Singh, H. Anti-inflammatory action of ferulic acid and its esters in carrageenan induced rat paw oedema model. Indian J. Exp. Biol. 1987, 25, 187-189.

86. Chotimarkorn, C.; Ushio, H. The effect of trans-ferulic acid and gamma-oryzanol on ethanol-induced liver injury in C57BL mouse. Phytomedicine 2008, 15, 951-958.

87. Nakashima, H.; Murakami, T.; Yamamoto, N.; Naoe, T.; Kawazoe, Y.; Konno, K.; Sakagami, H. Lignified materials as medicinal resources. V. Anti-HIV (human immunodeficiency virus) activity of some synthetic lignins. Chem. Pharm. Bull. (Tokyo) 1992, 40, 2102-2105.

88. Kikuzaki, H.; Hisamoto, M.; Hirose, K.; Akiyama, K.; Taniguchi, H. Antioxidant properties of ferulic acid and its related compounds. J. Agric. Food Chem. 2002, 50, 2161-2168.

89. Castelluccio, C.; Paganga, G.; Melikian, N.; Bolwell, G.P.; Pridham, J.; Sampson, J.; Rice-Evans, C. Antioxidant potential of intermediates in phenylpropanoid metabolism in higher plants. FEBS Lett. 1995, 368, 188-192.

90. Kono, Y.; Kobayashi, K.; Tagawa, S.; Adachi, K.; Ueda, A.; Sawa, Y.; Shibata, H. Antioxidant activity of polyphenolics in diets. Rate constants of reactions of chlorogenic acid and caffeic acid with reactive species of oxygen and nitrogen. Biochim. Biophys. Acta 1997, 1335, 335-342.

91. Gulcin, I. Antioxidant activity of caffeic acid (3,4-dihydroxycinnamic acid). Toxicology 2006, 217, 213-220.

92. Koshihara, Y.; Neichi, T.; Murota, S.; Lao, A.; Fujimoto, Y.; Tatsuno, T. Caffeic acid is a selective inhibitor for leukotriene biosynthesis. Biochim. Biophys. Acta 1984, 792, 92-97.

93. Nardini, M.; Leonardi, F.; Scaccini, C.; Virgili, F. Modulation of ceramide-induced NF-kappaB binding activity and apoptotic response by caffeic acid in U937 cells: comparison with other antioxidants. Free Radic. Biol. Med. 2001, 30, 722-733.

94. Mori, H.; Tanaka, T.; Shima, H.; Kuniyasu, T.; Takahashi, M. Inhibitory effect of chlorogenic acid on methylazoxymethanol acetate-induced carcinogenesis in large intestine and liver of hamsters. Cancer Lett. 1986, 30, 49-54.

95. Tanaka, T.; Kojima, T.; Kawamori, T.; Wang, A.; Suzui, M.; Okamoto, K.; Mori, H. Inhibition of 4-nitroquinoline-1-oxide-induced rat tongue carcinogenesis by the naturally occurring plant phenolics caffeic, ellagic, chlorogenic and ferulic acids. Carcinogenesis 1993, 14, 1321-1325. 
96. Tsuchiya, T.; Suzuki, O.; Igarashi, K. Protective effects of chlorogenic acid on paraquat-induced oxidative stress in rats. Biosci. Biotechnol. Biochem. 1996, 60, 765-768.

97. Hemmerle, H.; Burger, H.J.; Below, P.; Schubert, G.; Rippel, R.; Schindler, P.W.; Paulus, E.; Herling, A.W. Chlorogenic acid and synthetic chlorogenic acid derivatives: Novel inhibitors of hepatic glucose-6-phosphate translocase. J. Med. Chem. 1997, 40, 137-145.

98. Nardini, M.; D’Aquino, M.; Tomassi, G.; Gentili, V.; di Felice, M.; Scaccini, C. Inhibition of human low-density lipoprotein oxidation by caffeic acid and other hydroxycinnamic acid derivatives. Free Radic. Biol. Med. 1995, 19, 541-552.

99. Hsu, C.L.; Huang, S.L.; Yen, G.C. Inhibitory effect of phenolic acids on the proliferation of 3T3-L1 preadipocytes in relation to their antioxidant activity. J. Agric. Food Chem. 2006, 54, 4191-4197.

100. Naito, T.; Katsuhara, T.; Niitsu, K.; Ikeya, Y.; Okada, M.; Mitsuhashi, H. Phthalide dimers from Ligusticum chuanxiong Hort. Heterocycles 1991, 32, 2433-2442.

101. Naito, T.; Katsuhara, T.; Niitsu, K.; Ikeya, Y.; Okada, M.; Mitsuhashi, H. Two phthalides from Ligusticum chuanxiong. Phytochemistry 1992, 31, 639-642.

102. Naito, T.; Niitsu, K.; Ikeya, Y.; Okada, M.; Mitsuhashi, H. A phthalide and 2-farnesyl-6-methyl benzoquinone from Ligusticum chuanxiong. Phytochemistry 1992, 31, 1787-1789.

103. Naito, T.; Ikeya, Y.; Okada, M.; Mistuhashi, H.; Maruno, M. Two phthalides from Ligusticum chuanxiong. Phytochemistry 1996, 41, 233-236.

104. Li, Y.H.; Peng, S.L.; Zhou, Y.; Yu, K.B.; Ding, L.S. Two new phthalides from Ligusticum chuanxiong. Planta Med. 2006, 72, 652-656.

105. Chang, X.L.; Jiang, Z.Y.; Ma, Y.B.; Zhang, X.M.; Tsim, K.W.; Chen, J.J. Two new compounds from the roots of Ligusticum chuanxiong. J. Asian Nat. Prod. Res. 2009, 11, 805-810.

106. Guo, Z.F.; Wang, L.; Guo, T.T.; Song, C.Y.; Zhang, L.X. Analysis of the Chuanxiong ultrasonic extracts by GC-MS. J. Hebei Univ. (Nat. Sci. Ed.) 2009, 29, 177-183.

107. Mitsuhashi, H.; Muramatsu, T.; Nagai, U.; Nakano, T.; Ueno, K. Studies on the constituents of Umbelliferae plants. VIII. Distribution of alkylphthalides in umbelliferae plants. Chem. Pharm. Bull. (Tokyo) 1963, 11, 1317-1319.

108. Lim, L.S.; Shen, P.; Gong, Y.H.; Yong, E.L. Dimeric progestins from rhizomes of Ligusticum chuanxiong. Phytochemistry 2006, 67, 728-734.

109. Mitsuhashi, H.; Nagai, U.; Muramatsu, T. Studies on the constituents of Umbelliferae plants (III). Chem. Pharm. Bull. (Tokyo) 1961, 9, 115-119.

110. Cao, J.M.; Wang, Z.H.; Sun, G.P.; Ding, M.Y.; Yang, X.D.; Kou, H.J. Study on extraction and separation method for lactone components in Chuanxiong. Chin. J. Anal. Lab 2005, 24, 59-62.

111. Wang, X.Y.; Zheng, X.H.; Zhao, X.F.; Wang, R.; Wang, S.X. Optimization of the solid phase extraction of esters in the Chuanxiong water extracts. Chin. Tradit. Pat. Med. 2010, 32, $589-591$.

112. Zhang, Z.D.; Chen, J.P.; Li, C.P.; Yan, P.F.; Wang, A.J.; Urs, W.B. Microwave-assisted extraction of lactone from Ligusticum Chuanxiong Hort using ionic liquid. Chin. J. Process Eng. 2010, 10, 498-502. 
113. Zhang, X.Z.; Xu, Q.; Xiao, H.B.; Liang, X.M. Preparation of senkyunolide I by reversed-phase high performance liquid chromatography. Chin. J. Chromatogr. 2004, 22, 41-43.

114. Ito, Y. Golden rules and pitfalls in selecting optimum conditions for high-speed counter-current chromatography. J. Chromatogr. A 2005, 1065, 145-168.

115. Liu, W.; Wu, P.; Zhuo, C.; Zhang, J.Q.; Shen, P.N. One step separation and preparation of senkyunolide A and Z-ligustilide in Ligusticum chuanxiong Hort by high speed counter current chromatography. Chin. Tradit. Pat. Med. 2010, 32, 764-767.

116. Wu, G.T.; Shi, L.F.; Hu, J.H.; Li, L. Determination of ligustilide content in Chuanxiong by supercritical fluid extraction method. Acta Pharm. Sin. 1998, 33, 457-460.

117. Chao, Z.Z.; Chao, R.B. Determination of ligustilide content in Chuanxiong by HPLC. West China J. Pharm. Sci. 2004, 19, 197-198.

118. Lin, Y.Z.; Tang, X.; Bi, K.S. Determination of ligustilide in the volatile oil of Chuanxiong content by RP-HPLC. China J. Chin. Mat. Med. 2004, 29, 63-66.

119. Kong, L.; Yu, Z.Y.; Zou, H.F.; Sun, N.C.; Wu, L.H.; Ni, J.Y. Determination of the active ingredient of ferulic acid and ligustilide in Chuanxiong by HPLC-MS. Chin. J. Anal. Chem. 2004, 32, 1421-1425.

120. Hu, J.; Feng, L.L.; Liu, Y.; Cui, F.D. Determination and the study of alcohol extraction process of ligustilide in Danggui and Chuanxiong. J. Shenyang Pharm. Univ. 2005, 22, 145-148.

121. Cheng, S.Q.; Lv, G.H.; Liang, S.X.; Wang, Y.; Xu, Y.C.; Zhao, Z.Z. Determination of ligustilide for quality assessment of Ligusticum chuanxiong. China J. Chin. Mat. Med. 2006, 31, $1143-1146$.

122. Shan, J.J.; Di, L.Q. Determination the butylphthalide content in the volatile oil of chuanxiong by RP-HPLC method. J. Nanjing TCM Univ. 2006, 22, 94-95.

123. Shan, J.J.; Di, L.Q.; Luo, X.H.; Chen, H. Determination the butylphthalide content of chuanxiong by RP-HPLC method. Chin. Tradit. Herb. Drugs 2006, 37, 281-282.

124. Zhang, J.L.; He, X.F.; Zhou, Z.H. HPLC determination of five constituents in plants of genus Ligusticum. Acta Pharm. Sin. 1996, 31, 622-625.

125. Tang, Y.P.; Zhu, M.; Yu, S.; Hua, Y.Q.; Duan, J.A.; Su, S.L.; Zhang, X.; Lu,Y.; Ding, A.W. Identification and comparative quantification of bio-active phthalides in essential oils from si-wu-tang, fo-shou-san, radix angelica and rhizoma chuanxiong. Molecules 2010, 15, 341-351.

126. Shi, L.F.; Deng, Y.Z.; Wu, B.S. Studies on chemical constituents and their stability of the essential oil from dry rhizome of Ligusticum chuanxiong Hort. Chin. J. Pharm. Anal. 1995, 15, 26-30.

127. Li, G.S.; Ma, C.J.; Li, X.Y.; Liu, K. Studies on the stability of ligustilide and the analysis of its isomerized products by GC-MS. Chin. Tradit. Herb. Drugs 2000, 31, 405-407.

128. Zschocke, S.; Liu, J.H.; Stuppner, H.; Bauer, R. Comparative study of roots of Angelica sinensis and related umbelliferous drugs by thin layer chromatography, high-performance liquid chromatography, and liquid chromatography-mass spectrometry. Phytochem. Anal. 1998, 9, 283-290.

129. Yi, T.; Leung, K.S.; Lu, G.H.; Zhang, H.; Chan, K. Identification and comparative determination of senkyunolide A in traditional Chinese medicinal plants Ligusticum chuanxiong and 
Angelica sinensis by HPLC coupled with DAD and ESI-MS. Chem. Pharm. Bull. (Tokyo) 2005, $53,1480-1483$.

130. Yi, T.; Leung, K.S.; Lu, G.H.; Chan, K.; Zhang, H. Simultaneous qualitative and quantitative analyses of the major constituents in the rhizome of Ligusticum Chuanxiong using HPLC-DAD-MS. Chem. Pharm. Bull. (Tokyo) 2006, 54, 255-259.

131. Wang, Z.J.; Wo, S.K.; Wang, L.; Lau, C.B.; Lee, V.H.; Chow, M.S.; Zuo, Z. Simultaneous quantification of active components in the herbs and products of Si-Wu-Tang by high performance liquid chromatography-mass spectrometry. J. Pharm. Biomed. Anal. 2009, 50, 232-244.

132. Gijbels, M.J.M.; Scheffer, J.J.C.; Svendsen, A.B. Analysis of phthalides from umbelliferae by combined liquid-solid and gas-liquid chromatography. Chromatographia 1981, 14, 452-454.

133. Almeida, C.; Kehraus, S.; Prudencio, M.; Konig, G.M. Marilones A-C, phthalides from the sponge-derived fungus Stachylidium sp. Beilstein J. Org. Chem. 2011, 7, 1636-1642.

134. Beck, J.J.; Chou, S.C. The structural diversity of phthalides from the Apiaceae. J. Nat. Prod. 2007, 70, 891-900.

135. Cao, Y.X.; Zhang, W.; He, J.Y.; He, L.C.; Xu, C.B. Ligustilide induces vasodilatation via inhibiting voltage dependent calcium channel and receptor-mediated $\mathrm{Ca}^{2+}$ influx and release. Vasc. Pharmacol. 2006, 45, 171-176.

136. Hu, Y.; Liang, Y.Z.; Li, B.Y.; Li, X.N.; Du, Y.P. Multicomponent spectral correlative chromatography applied to complex herbal medicines. J. Agric. Food Chem. 2004, 52, 7771-7776.

137. Tao, J.Y.; Ruan, Y.P.; Mei, Q.B.; Liu, S.; Tian, Q.L.; Chen, Y.Z.; Zhang, H.D.; Duan, Z.X. Studies on the antiasthmatic action of ligustilide of dang-gui, Angelica sinensis (Oliv.) Diels. Acta Pharm. Sin. 1984, 19, 561-565.

138. Zhang, L.; Du, J.R.; Wang, J.; Yu, D.K.; Chen, Y.S.; He, Y.; Wang, C.Y. Z-ligustilide extracted from Radix Angelica Sinensis decreased platelet aggregation induced by ADP ex vivo and arterio-venous shunt thrombosis in vivo in rats. Yakugaku Zasshi 2009, 129, 855-859.

139. Du, J.R.; Yu, Y.; Ke, Y.; Wang, C.Y.; Zhu, L.; Qian, Z.M. Ligustilide attenuates pain behavior induced by acetic acid or formalin. J. Ethnopharmacol. 2007, 112, 211-214.

140. Lu, Q.; Qiu, T.Q.; Yang, H. Ligustilide inhibits vascular smooth muscle cells proliferation. Eur. J. Pharmacol. 2006, 542, 136-140.

141. Ozaki, Y.; Sekita, S.; Harada, M. Centrally acting muscle relaxant effect of phthalides (ligustilide, cnidilide and senkyunolide) obtained from Cnidium officinale Makino. Yakugaku Zasshi 1989, 109, 402-406.

142. Matsumoto, K.; Kohno, S.; Ojima, K.; Tezuka, Y.; Kadota, S.; Watanabe, H. Effects of methylenechloride-soluble fraction of Japanese angelica root extract, ligustilide and butylidenephthalide, on pentobarbital sleep in group-housed and socially isolated mice. Life Sci. 1998, 62, 2073-2082.

143. Wu, X.M.; Qian, Z.M.; Zhu, L.; Du, F.; Yung, W.H.; Gong, Q.; Ke, Y. Neuroprotective effect of ligustilide against ischaemia-reperfusion injury via up-regulation of erythropoietin and down-regulation of RTP801. Br. J. Pharmacol. 2011, 164, 332-343. 
144. Peng, H.Y.; Du, J.R.; Zhang, G.Y.; Kuang, X.; Liu, Y.X.; Qian, Z.M.; Wang, C.Y. Neuroprotective effect of Z-ligustilide against permanent focal ischemic damage in rats. Biol. Pharm. Bull. 2007, 30, 309-312.

145. Kuang, X.; Yao, Y.; Du, J.R.; Liu, Y.X.; Wang, C.Y.; Qian, Z.M. Neuroprotective role of Z-ligustilide against forebrain ischemic injury in ICR mice. Brain Res. 2006, 1102, 145-153.

146. Liu, L.; Ning, Z.Q.; Shan, S.; Zhang, K.; Deng, T.; Lu, X.P.; Cheng, Y.Y. Phthalide lactones from Ligusticum chuanxiong inhibit lipopolysaccharide-induced TNF-alpha production and TNF-alpha-mediated NF-kappaB activation. Planta Med. 2005, 71, 808-813.

147. Chan, S.S.; Cheng, T.Y.; Lin, G. Relaxation effects of ligustilide and senkyunolide A, two main constituents of Ligusticum chuanxiong, in rat isolated aorta. J. Ethnopharmacol. 2007, 111, $677-680$.

148. Liang, M.J.; He, L.C. Inhibitory effects of ligustilide and butylidenephthalide on bFGF-stimulated proliferation of rat smooth muscle cells. Acta Pharm. Sin. 2006, 41, 161-165.

149. Wang, Y.X.; Gao, X.L.; Wang, P.S.; Fushan, A.B.; Shanxia, X.S. Study of the another active constituents of chuanxiong. Chin. Tradit. Herb. Drugs 1985, 16, 17-18.

150. Liu, B.; John, R.D.; Rachel, P. Extraction of tetramethylpyrazine from Ligusticum chuanxiong Hort using phytosol solvent and supercritical fluid. Chin. J. Pharm. 1999, 30, 196-199.

151. Yang, H.; Liu, L.; Zhang, H.J. Study for the extraction process and quality standards of tetramethylpyrazine. Chin. J. Ethnomed. Ethnopharm. 2009, 4, 24-40.

152. Li, X.Y.; Guan, Y.T.; Huang, A.B.; Liang, X.F.; Lei, F.H. Study on optimum ultrasonic extraction process of ligustrazine hydrochloride from Ligusticum chuanxiong Hort. by orthogonal design. Lishizhen Med. Mat. Med. Res. 2009, 20, 1990-1992.

153. Dai, L. Study on ultrafine vibration extraction technology of Rhizoma Chuanxiong. China J. Chin. Mat. Med. 2009, 34, 977-979.

154. Sun, X.G.; Wang, T.; Zhu, J.S. Determination of TMP content in Chuanxiong by counter current extraction-High performance liquid chromatography. Acta Univ. Med. Tongji 2001, 30, 209-210.

155. Li, H.B.; Chen, F. Preparative isolation and purification of chuanxiongzine from the medicinal plant Ligusticum chuanxiong by high-speed counter-current chromatography. J. Chromatogr. A 2004, 1047, 249-253.

156. Ma, L.; Wang, X.J.; Zhang, J.; Zhao, Q.D.; Chen, Z.J. Explore the best extractive craft of tetramethylpyrazine from Rhizoma Chuanxiong. Lishizhen Med. Mat. Med. Res. 2007, 18, 3057-3058.

157. He, Z.Y.; Liu, Y.; Jia, M.R.; Qiang, Y.; Ma, Y.Y.; Chen, K.; Zhang, Y.; Jiang, G. Determination of the total alkaloids contents from Ligusticum chuanxiong (Naichuanxiong, Shanchuanxiong and Rhizoma chuanxiong). West China J. Pharm. Sci. 2004, 19, 292-293.

158. Wang, S.B.; Song, H.G. Colorimetric determination of total alkaloids in Ligusticum chuanxiong with reinecke salt. Cent. South Pharm. 2009, 7, 824-826.

159. Li, S.L. Determination of alkaloid content in different processed products of Chuanxiong. J. Henan Coll. Tradit. Chin. Med. 2001, 16, 18-19.

160. Sheu, J.R.; Kan, Y.C.; Hung, W.C.; Lin, C.H.; Yen, M.H. The antiplatelet activity of tetramethylpyrazine is mediated through activation of NO synthase. Life Sci. 2000, 67, 937-947. 
161. Pang, P.K.; Shan, J.J.; Chiu, K.W. Tetramethylpyrazine, a calcium antagonist. Planta Med. 1996, $62,431-435$.

162. Zhang, Z.H.; Wei, T.T.; Hou, J.W.; Li, G.S.; Yu, S.Z.; Xin, W.J. Tetramethylpyrazine scavenges superoxide anion and decreases nitric oxide production in human polymorphonuclear leukocytes. Life Sci. 2003, 72, 2465-2472.

163. Huang, Y.T.; Chang, F.C.; Chen, K.J.; Hong, C.Y. Acute hemodynamic effects of tetramethylpyrazine and tetrandrine on cirrhotic rats. Planta Med. 1999, 65, 130-134.

164. Liu, C.F.; Lin, C.C.; Ng, L.T.; Lin, S.C. Hepatoprotective and therapeutic effects of tetramethylpyrazine on acute econazole-induced liver injury. Planta Med. 2002, 68, 510-514.

165. Wu, H.J.; Hao, J.; Wang, S.Q.; Jin, B.L.; Chen, X.B. Protective effects of ligustrazine on TNF-alpha-induced endothelial dysfunction. Eur. J. Pharmacol. 2012, 674, 365-369.

166. Feng, L.; Xiong, Y.; Cheng, F.; Zhang, L.; Li, S.; Li, Y. Effect of ligustrazine on ischemia-reperfusion injury in murine kidney. Transplant. Proc. 2004, 36, 1949-1951.

167. Gao, C.; Feng, L.; Li, Y.P.; Cheng, Y. Effect of ligustrazine on chronic allograft nephropathy in rats. Transplant. Proc. 2007, 39, 3415-3419.

168. Zhang, Z.H.; Wei, T.T.; Hou, J.W.; Li, G.S.; Yu, S.Z.; Xin, W.J. Iron-induced oxidative damage and apoptosis in cerebellar granule cells: Attenuation by tetramethylpyrazine and ferulic acid. Eur. J. Pharmacol. 2003, 467, 41-47.

169. Liao, S.L.; Kao, T.K.; Chen, W.Y.; Lin, Y.S.; Chen, S.Y.; Raung, S.L.; Wu, C.W.; Lu, H.C.; Chen, C.J. Tetramethylpyrazine reduces ischemic brain injury in rats. Neurosci. Lett. 2004, 372, $40-45$.

170. Fan, L.H.; Wang, K.Z.; Cheng, B.; Wang, C.S.; Dang, X.Q. Anti-apoptotic and neuroprotective effects of Tetramethylpyrazine following spinal cord ischemia in rabbits. BMC Neurosci. 2006, 7,48 .

171. Cheng, X.R.; Zhang, L.; Hu, J.J.; Sun, L.; Du, G.H. Neuroprotective effects of tetramethylpyrazine on hydrogen peroxide-induced apoptosis in PC12 cells. Cell Biol. Int. 2007, 31, 438-443.

172. Fan, Z.C.; Zhang, Z.Q. Polysaccharides from Ligusticum chuanxiong. Chin. Tradit. Herb. Drugs 2006, 37, 973-976.

173. Fan, Z.C.; Zhang, Z.Q. Extraction, purification and anti-oxidative activities of polysaccharides from Ligusticum chuanxiong Hort. Nat. Prod. Res. Dev. 2005, 17, 561-567.

174. Zhao, L. The study on the separation, extraction and the relevant nature of Chuanxiong (Ligusticum Chuanxiong Hort.) saccharide substance. Master Thesis, Northeast Normal University, Changchun, China, 2006.

175. Sun, X.C.; Yan, J.; He, G.; Zhang, L.L.; Yi, Y.; Gou, X.J. Purification and analysis of monosaccharide composition of Ligusticum chuanxiong polysaccharide. J. Sichuan Agric. Univ. 2011, 29, 56-60.

176. Xiang, M.; Wang, X.J.; Wang, W.X. Optimization of the ultrasonic extraction process of Chuanxiong polysaccharide. Chin. Tradit. Pat. Med. 2008, 30, 1621-1623.

177. Li, L.; Wang, W.X.; Wang, X.J. Study of the pectinase extraction process of Chuanxiong polysaccharide. J. Chin. Med. Mat. 2008, 31, 600-602. 
178. Tang, Q.; Wang, W.X.; Wang, X.J. Extraction of polysaccharides from Ligusticum chuanxiong Hort by basic method. Lishizhen Med. Mat. Med. Res. 2008, 19, 2096-2097.

179. Ding, W.W.; Wang, W.X.; Wang, X.J. Extraction of polysaccharides from Ligusticum chuanxiong Hort by enzymatic method. J. Xihua Univ. (Nat. Sci.) 2008, 27, 42-43.

180. Huang, H.F.; Wang, W.X. Extraction of polysaccharides from Ligusticum chuanxiong Hort by microwave-assisted method. Lishizhen Med. Mat. Med. Res. 2009, 20, 2734-2735.

181. Sun, X.; Wang, W.X. Extraction of polysaccharides from Ligusticum chuanxiong Hort by cellulose enzyme method. J. Xihua Univ. (Nat. Sci.) 2009, 28, 103-106.

182. Aihemaiti, P.R.H.T.; Aihemaiti, S.D.; Xu, S.S.; Ji'er, G.L.; Wu, Q. Explore for the extracted process of the Chuanxiong polysaccharide separation. Friend Sci. Amateurs 2011, 3-4.

183. Wang, W.X.; Wang, X.J.; Huang, X.; Yang, W.Y. Comparison study of decolorization ways for polysaccharide from Ligusticum Chuanxiong Hort. Ion Exch. Adsorp. 2010, 24, 74-82.

184. Zhang, Z.Q.; Fan, Z.C.; Yan, H.T. Flow injection on-line hydrolytic spectrophotometry for the rapid determination of polysaccharide in Ligusticum chuanxiong Hort. Chin. J. Pharm. Anal. 2004, 24, 320-323.

185. Zhang, W.J.; Wang, P.; Yang, M.J.; Wang, Y.G.; Ju, Y.; Du, R.H. Analysis and comparison of polysaccharide activity of chuanxiong and chishao. J. Chin. Med. Mat. 2011, 34, 1569-1574.

186. Yang, N.Y.; Ren, D.C.; Duan, J.A.; Xu, X.H.; Xie, N.; Tian, L.J. Ceramides and cerebrosides from Ligusticum chuanxiong Hort. Helv. Chim. Acta 2009, 92, 291-297.

187. Han, X.; Cheng, H. Characterization and direct quantitation of cerebroside molecular species from lipid extracts by shotgun lipidomics. J. Lipid Res. 2005, 46, 163-175.

188. Chen, Y.; Lü, J.L.; Duan, J.A.; Jiang, L.H.; Guo, J.M. Distribution of cerebroside from a viewpoint of organic evolution and advances of its biological activity. J. Int. Pharm. Res. 2009, $36,121-126$.

189. Nie, H.D.; Hao, R. Study of the chemical constituents of the Chuanxiong ground part. Med. Inform. 2011, 326, 326-328.

190. Hao, S.J.; Zhang, Z.X.; Tian, Y.; Ma, Y.P.; Peng, B.; Shen, S.; Zhang, L.; Wang, J.H. Study on chemical constituents of Ligusticum chuanxiong Hort. Mod. Chin. Med. 2010, 12, 22-38.

191. Miao, C.; Wu, S.; Luo, B.; Wang, J.; Chen, Y. A new sesquiterpenoid from Ligusticum chuanxiong Hort. Fitoterapia 2010, 81, 1088-1090.

192. Li, S.L.; Chan, S.S.; Lin, G.; Ling, L.; Yan, R.; Chung, H.S.; Tam, Y.K. Simultaneous analysis of seventeen chemical ingredients of Ligusticum chuanxiong by on-line high performance liquid chromatography-diode array detector-mass spectrometry. Planta Med. 2003, 69, 445-451.

193. Yan, R.; Li, S.L.; Chung, H.S.; Tam, Y.K.; Lin, G. Simultaneous quantification of 12 bioactive components of Ligusticum chuanxiong Hort. by high-performance liquid chromatography. J. Pharm. Biomed. Anal. 2005, 37, 87-95.

194. Sun, G.P.; Yang, X.D.; Wang, Q.E.; Ding, M.Y. Quantitative determination of total senkyunolides in Rhizoma Chuanxiong by UV spectrophotometry. Chin. J. Anal. Lab 2007, 26, 9-11.

195. Teng, J.W.; Li, D.L.; Luo, A.D. Identification and characterization of supercritical fluid extracts of Rhizoma Chuanxiong by high performance liquid chromatography-Ion trap mass spectrometry. J. Chin. Mass Spectrom. Soc. 2007, 26, 356-359. 
196. Teng, J.W.; Chen, H.W.; Li, D.L.; Luo, A.D. Identification and characterization of supercritical fluid extracts of Rhizoma Chuanxiong by high performance liquid chromatography ion trap mass spectrometry. Front. Chem. China 2006, 1, 454-458.

197. Yi, T.; Leung, K.S.; Lu, G.H.; Zhang, H. Comparative analysis of Ligusticum chuanxiong and related umbelliferous medicinal plants by high performance liquid chromatography-Electrospray ionization mass spectrometry. Planta Med. 2007, 73, 392-398.

198. Yao, Z.L.; Du, S.Y.; Lu, Y.; Xu, B.; Chen, X.L. Simultaneous determination of active ingredient content of five kinds of different sources of Chuanxiong by RP-HPLC. China J. Chin. Mat. Med. 2010, 35, 2696-2699.

199. Wang, Y.M.; Zhang, H.F.; Yan, B.Q.; Chen, X.H.; Bi, K.S. Determination of ferulic acid, 6,7-di-hydroxyligustilide and 4-hydroxy-3-butylphthalide in Rhizoma Chuanxiong by HPLC. Chin. J. Pharm. Anal. 2009, 29, 2109-2112.

200. Wu, P.L.; Liu, W.; Zhang, J.Q.; Shen, P.R.; Zhuo, C. Determination of senkyunolide A and Z-ligustilide in Ligusticum Chuanxiong Hort. by HPLC. Chin. J. Pharm. 2010, 41, 290-292.

201. Li, W.X.; Wang, H.; Tang, Y.P.; Guo, J.M.; Qian, D.W.; Ding, A.W.; Duan, J.A. The quantitative comparative analysis for main bio-active components in Angelica sinensis, Ligusticum chuanxiong and the herb pair Gui-Xiong. J. Liq. Chromatogr. R. T. 2012, in press.

202. Zschocke, S.; Klaiber, I.; Bauer, R.; Vogler, B. HPLC-coupled spectroscopic techniques (UV, MS, NMR) for the structure elucidation of phthalides in Ligusticum chuanxiong. Mol. Divers. 2005, 9, 33-39.

203. Zhang, X.Z.; Xiao, H.B.; Xu, Q.; Li, X.L.; Wang, J.N.; Liang, X.M. Characterization of phthalides in Ligusticum chuanxiong by liquid chromatographic-atmospheric pressure chemical ionization-mass spectrometry. J. Chromatogr. Sci. 2003, 41, 428-433.

204. Hu, L.H.; Chen, X.G.; Kong, L.; Su, X.Y.; Ye, M.L.; Zou, H.F. Improved performance of comprehensive two-dimensional HPLC separation of traditional Chinese medicines by using a silica monolithic column and normalization of peak heights. J. Chromatogr. A 2005, 1092, 191-198.

205. Chen, X.G.; Kong, L.; Su, X.Y.; Fu, H.J.; Ni, J.Y.; Zhao, R.H.; Zou, H.F. Separation and identification of compounds in Rhizoma chuanxiong by comprehensive two-dimensional liquid chromatography coupled to mass spectrometry. J. Chromatogr. A 2004, 1040, 169-178.

206. Chen, Q.H.; Li, P.; Li, B.; Yang, H.D.; Li, X.L.; Chen, F.C. A GC-MS-SIM simultaneous determination of ligustilide and butylidenephthalide from Ligusticum chuanxiong using SFE. Chromatographia 2010, 72, 963-967.

207. Li, Z.W.; Zhang, Q. Separation and identification of lactone components in Ligusticum chuanxiong and Cnidium officinale by GC-MS. Chin. J. Pharm. Anal. 1993, 13, 187-189.

208. Zhou, B.J.; Zhang, Z.Y.; Shi, Y.; Gu, W.X.; Zhang, S.Y. Extraction, separation and GC/MS analysis of Chuanxiong volatile components extracted by supercritical $\mathrm{CO}_{2}$ fluid extraction and molecular distillation. J. First Mil. Med. Univ. 2002, 22, 652-653.

209. Gong, F.; Liang, Y.Z.; Chau, F.T. Combination of GC-MS with local resolution for determining volatile components in si-wu decoction. J. Sep. Sci. 2003, 26, 112-122.

210. Xu, J.Y.; Zhu, Z.S.; Yu, W.B. Component analysis by GC-MS of the Chuanxiong pieces extracted with alcohol. Guangdong Pharm. J. 2005, 15, 3-4. 
211. Zhang, D.L.; Li, G.S.; Ren, Z.Y.; Qu, G.W. GC quantitative determination of Z-ligustilide and senkyunolide A in essential oil of Ligusticum chuanxiong Hort. Chin. J. Pharm. Anal. 2006, 26, 895-897.

212. Li, X.R.; Liang, Y.Z.; Guo, F.Q. Analysis of volatile oil in Rhizoma ligustici chuanxiong-Radix paeoniae rubra by gas chromatography-mass spectrometry and chemometric resolution. Acta Pharmacol. Sin. 2006, 27, 491-498.

213. Zhang, C.; Qi, M.L.; Shao, Q.L.; Zhou, S.; Fu, R.N. Analysis of the volatile compounds in Ligusticum chuanxiong Hort. using HS-SPME-GC-MS. J. Pharm. Biomed. Anal. 2007, 44, 464-470.

214. Wang, N.; Zhang, Y.; Li, X.; Tong, Y.P.; Kong, H.W.; Xu, G.W. Analysis of volatile oils of Ligusticum chuanxiong Hort. from different geographical origins by comprehensive two-dimensional gas chromatography/time-of-flight mass spectrometry. Se $P u \mathbf{2 0 1 0}, 28$, 329-335.

215. Chu, Q.C.; Zhang, D.L.; Zhang, H.T.; Ye, J.N. Study on Rhizoma Chuanxiong based on capillary electrophoresis with amperometric detection. Chin. Chem. Lett. 2010, 21, 217-220.

216. Jorgenson, J.W.; Lukacs, K.D. Zone electrophoresis in open-tubular glass capillaries. Anal. Chem. 1981, 53, 1298-1302.

217. Hau, F.C.R.; Morrison, P.D.; Small, D.M.; Marriott, P.J. Investigation of folic acid stability in fortified instant noodles by use of capillary electrophoresis and reversed-phase high performance liquid chromatography. J. Chromatogr. A 2008, 1213, 93-99.

218. Wei, F.H.; Xiao, Y.C.; Luo, Q.Q.; Sun, X.G. HPCE studies of the chemical profile of Chuanxiong water extraction. J. Chin. Med. Mat. 2008, 31, 1149-1151.

219. Zhang, K.; Gao, R.Y.; Jiang, Z.J.; Yao, C.Y.; Zhang, Z.C.; Wang, Q.S.; Yan, C. Pressurized capillary electrochromatography separation of peptides with strong cation exchange and hydrophilic interaction. J. Sep. Sci. 2003, 26, 1389-1394.

220. Lu, H.X.; Wang, J.B.; Wang, X.C.; Lin, X.C.; Wu, X.P.; Xie, Z.H. Rapid separation and determination of structurally related anthraquinones in Rhubarb by pressurized capillary electrochromatography. J. Pharm. Biomed. Anal. 2007, 43, 352-357.

221. Xie, G.X.; Zhao, A.H.; Li, P.; Li, L.; Jia, W. Fingerprint analysis of Rhizoma chuanxiong by pressurized capillary electrochromatography and high-performance liquid chromatography. Biomed. Chromatogr. 2007, 21, 867-875.

222. Gan, F.; Ye, R.Y. New approach on similarity analysis of chromatographic fingerprint of herbal medicine. J. Chromatogr. A 2006, 1104, 100-105.

223. Wei, G.; Cai, Q.Q.; Huang, Y.C.; Liu, C.L. Analysis on correlation of HPLC fingerprint on decoction pieces and decoction of Rhizoma Ligusticum. Chin. J. Exp. Tradit. Med. Formulae 2011, 17, 46-49.

224. Sun, Y.; Guo, T.; Sui, Y.; Li, F.M. HPCE-FP methodology study of Chuanxiong. China J. Chin. Mat. Med. 2003, 28, 167-171.

225. Qin, H.L.; Deng, A.J.; Du, G.H.; Wang, P.; Zhang, J.L.; Li, Z.H. Fingerprinting analysis of Rhizoma Chuanxiong of commercial types using H-1 nuclear magnetic resonance spectroscopy and high performance liquid chromatography method. J. Integr. Plant Biol. 2009, 51, 537-544. 
226. Li, S.L.; Lin, G.; Chung, H.S.; Tamy, Y.K. Study on fingerprint of Rhizoma Chuanxiong by HPLC-DAD-MS. Acta Pharm. Sin. 2004, 39, 621-626.

227. Gong, F.; Liang, Y.Z.; Xie, P.S.; Chau, F.T. Information theory applied to chromatographic fingerprint of herbal medicine for quality control. J. Chromatogr. A 2003, 1002, 25-40.

228. Yang, B.J.; Chen, J.H.; Lee, F.S.C.; Wang, X.R. GC-MS fingerprints for discrimination of Ligusticum chuanxiong from Angelica. J. Sep. Sci. 2008, 31, 3231-3237.

229. Qin, H.L.; Li, Z.H.; Wang, P.; Yang, J.R. Specific control substance analysis and its creation of the fingerprint of Huanglian. Acta Acad. Med. Sin. 2004, 26, 622-627.

230. Su, D.M.; Han, J.L.; Yu, S.S.; Qin, H.L. Assessment of ${ }^{1}$ H-NMR spectroscopy for specific metabolite fingerprinting of Angelica sinensis. Nat. Prod. Commun. 2008, 3, 727-730.

231. Wren, S.A. Peak capacity in gradient ultra performance liquid chromatography (UPLC). J. Pharm. Biomed. Anal. 2005, 38, 337-343.

232. Wang, C.; Feng, R.N.; Sun, D.J.; Li, Y.; Bi, X.X.; Sun, C.H. Metabolic profiling of urine in young obese men using ultra performance liquid chromatography and Q-TOF mass spectrometry (UPLC/Q-TOF MS). J. Chromatogr. B Anal. Technol. Biomed. Life Sci. 2011, 879, 2871-2876.

233. Wang, X.J.; Sun, W.J.; Sun, H.; Lv, H.T.; Wu, Z.M.; Wang, P.; Liu, L.; Cao, H.X. Analysis of the constituents in the rat plasma after oral administration of Yin Chen Hao Tang by UPLC/Q-TOF-MS/MS. J. Pharm. Biomed. Anal. 2008, 46, 477-490.

234. Zhou, Y.; Li, N.; Choi, F.F.K.; Qiao, C.F.; Song, J.Z.; Li, S.L.; Liu, X.; Cai, Z.W.; Fu, P.P.; Lin, G.; et al. A new approach for simultaneous screening and quantification of toxic pyrrolizidine alkaloids in some potential pyrrolizidine alkaloid-containing plants by using ultra performance liquid chromatography-tandem quadrupole mass spectrometry. Anal. Chim. Acta 2010, 681, 33-40.

235. Krzyzanowska, J.; Janda, B.; Pecio, L.; Stochmal, A.; Oleszek, W.; Czubacka, A.; Przybys, M.; Doroszewska, T. Determination of polyphenols in Mentha longifolia and M. piperita field-grown and in vitro plant samples using UPLC-TQ-MS. J. AOAC Int. 2011, 94, 43-50.

(C) 2012 by the authors; licensee MDPI, Basel, Switzerland. This article is an open access article distributed under the terms and conditions of the Creative Commons Attribution license (http://creativecommons.org/licenses/by/3.0/). 